\title{
A Nova Configuração Regional Brasileira e sua Geografia Econômica
}

Mauro Borges Lemos
Clelio Campolina Diniz
Leonardo Pontes Guerra

Sueli Moro
Professor do CEDEPLAR - FACE/UFMG

Professor do CEDEPLAR - FACE/UFMG

Secretário Municipal de Modernização e Reforma

Administrativa, Prefeitura de Belo Horizonte

Professora do CEDEPLAR - FACE/UFMG

\section{RESUMO}

O objetivo deste trabalho é identificar a nova configuração regional brasileira, procurando delimitar seus pólos econômicos e suas áreas de influência, como base para uma proposta de nova regionalização para o Brasil. Para isto, é construída uma metodologia específica, baseada na aplicação do Modelo Gravitacional, comumente usado em estudos espaciais, por meio do Sistema de Informações Geográficas - SIG. Este procedimento possibilita a identificação das regiões-pólos e suas áreas de influência, com base no potencial de interação econômica entre as unidades espaciais e na correspondente hierarquia de poder de atração econômica no espaço. As microrregiões geográficas (MRGs) do IBGE constituem a unidade espacial básica deste estudo, que se baseia nos microdados do Censo Demográfico de 1991. A base cartográfica digital foi a Malha Municipal Digital do Brasil, convertida para o Mapinfo. A regionalização final incorpora, em seus resultados, uma qualificação da fricção espacial.

\section{PALAVRAS-CHAVE}

economia regional, geografia econômica, regionalização econômica, sistema de informação geográfica (SIG), Brasil

\section{ABSTRACT}

The aim of this paper is to identify the new regional pattern of the Brazilian economy by defining its economic poles and their areas of polarization, which will provide an economic regionalization for Brazil. The methodological tools to assign this objective will be an adapted version of the gravitational model using the Geographic Information System - GIS. This procedure will allow the identification of the influence areas for each regional pole, based on the potential interaction among the spatial units and their hierarchy in terms of economic power of attraction. The microregion of the Brazilian Statistics Bureau (IBGE) will be the spatial unit of this study, which will rely on microdata of the 199I Demographic Census. The digital cartographic base is the Brazilian Municipal Digital Network converted into the Maplnfo. The results will provide a hierarchical spatial structure of macro regions, mesoregions, microregions, and municipalities. In addition, we will make a basic economic characterization of the regions related to their agglomeration capability and economic activities.

KEY WORDS regional economics, economic geography, economic regionalization, geographic information system (GIS), Brazil.

\section{JEL Classification}




\section{INTRODUÇÃO}

O objetivo deste trabalho é identificar a nova configuração regional brasileira, procurando delimitar seus pólos econômicos e suas áreas de influência, como base para uma proposta de nova regionalização do Brasil, consideradas três escalas territoriais (micro, meso e macrorregiões). A seção l discute, sucintamente, o marco teórico da proposta de regionalização econômica. Partimos da abordagem de lugar central e área de mercado para a construção, na seção 2 , de uma metodologia específica baseada na aplicação do Modelo Gravitacional, comumente usado em estudos espaciais, por meio do Sistema de Informações Geográficas - SIG. Este procedimento possibilita a identificação das regiões-pólos e suas áreas de influência com base no potencial de interação econômica entre as unidades espaciais e na correspondente hierarquia de poder de atração econômica no espaço. As microrregióes geográficas (MRGs) do IBGE constituem a unidade espacial básica deste estudo, que se baseia nos microdados do Censo Demográfico de 1991. A base cartográfica digital foi a Malha Municipal Digital do Brasil, convertida para o Mapinfo. Os resultados da regionalização final, na seção 3 , incorporam uma qualificação da fricção espacial, principalmente no aspecto da acessibilidade. ${ }^{1}$

Este esforço de se estabelecer uma nova regionalização e entender a dinâmica eminentemente urbana do espaço econômico brasileiro soma-se a outros estudos recentes realizados no País. ${ }^{2}$ Um estudo pioneiro na linha teórico-metodológica, utilizada neste trabalho, foi o desenvolvido por Lemos (1991), aqui adotado como ponto de referência. Os estudos empíricos básicos, contemporâneos, sobre a hierarquia urbana no Brasil foram desenvolvidos, no início dos anos noventa, pelo Departamento de Geografia do IBGE - DEGEO, denominados Rede de influência das cidades,

1 Uma regionalização para fins de planejamento e de políticas públicas deveria também incluir a análise da representação política, dada a divisão político-administrativa prévia do território brasileiro em Estados e municípios. Os aspectos do meio ambiente deveriam ser igualmente considerados. Embora relevantes, esses aspectos não foram incorporados neste trabalho.

2 Um dos estudos pioneiros anteriores no Brasil foi realizado por FERREIRA (1971). 
1993, Aglomeraçôes urbanas para fins estatístico e Tipologia dos municípios brasileiros, e serviram de base de referência metodológica e empírica para o trabalho IPEA/IBGE/NESUR (1999), o qual, de forma exaustiva, analisa o perfil e as transformaçóes da rede urbana do Brasil. Certamente, este último trabalho converge para a linha de investigação da pesquisa que sustenta o presente artigo, com importantes similaridades metodológicas e dos achados empíricos. Como deve ficar claro ao longo do artigo, existem, entretanto, diferenças no tratamento do conceito de região e na metodologia utilizada. O conceito eminentemente econômico utilizado por nós na delimitação de uma região contrasta com a concepção um tanto dúbia encontrada no referido trabalho. Se, por um lado, concebe o centro urbano como o elemento organizador do espaço econômico, fica preso, por outro lado, à divisão político-administrativa de região, a qual não corresponde, no entanto, à delimitação estabelecida pela dinâmica de constituição das economias urbanas e seus centros de polarização. Entendemos, ao contrário, que a região deva ser parte indissociável da definição de centro urbano ou lugar central.

\section{1. ÁREA DE MERCADO, HIERARQUIA URBANA E O MODE- LO GRAVITACIONAL}

O marco teórico que sustenta nossa delimitação de região são as concepções de lugar central e área de mercado, originalmente desenvolvidas por Christaller (1966) [1933] e Lösch (1954) [1940], respectivamente. O lugar central, o núcleo urbano original, constitui-se no elemento organizador da curva de oferta e demanda de bens no espaço, que delimita a área de mercado em que ocorre forte intensidade do fluxo de trocas, em uma área geográfica espacialmente delimitada. A extensão da área de mercado é, entretanto, permanentemente restringida pelo atrito espacial da distância, no sentido de que a curva de demanda dos bens no espaço é função inversa do crescimento dos custos totais de transporte. Nesta acepção, este espaço geográfico, caracterizado por fortes relações de trocas internas e fracas relações externas, denomina-se região, em termos estritamente econômicos. A contribuição específica de North (1955), para uma definição mais completa de região, foi a de fornecer elementos teóricos para romper com a natureza de economia 
fechada, subjacente, da definição original, pela introdução da idéia de base exportadora regional. A partir da exploração de vantagens comparativas, a exportação de bens para localidades fora da área de mercado regional constitui fator decisivo de integração inter-regional e realimentação do crescimento do lugar central, em função de retornos crescentes de escala ou economias de especialização regional. (FUJITA et al., 1999, p. 28). Por sua vez, a expansão da oferta de bens residenciais de baixa transportabilidade, constituídos fundamentalmente pelos serviços, constitui fator decisivo de consolidação da integração intra-regional e desenvolvimento de economias de urbanização. (RICHARDSON, 1973).

À medida que o espaço econômico tende a se organizar no entorno de vários lugares centrais, com suas áreas de mercado, está aberta a possibilidade de reprodução de regiões e desenvolvimento de economias regionais, com níveis diferenciados de integração econômica. Ao mesmo tempo, do ponto de vista intra-regional, podem se desenvolver lugares centrais diferenciados, por ordem de tamanho e funcionalidade na oferta de bens, de maneira a se conformar sistemas urbanos hierarquizados. Configura-se, assim, uma hierarquia nodal urbana, formada pelo centro de maior tamanho, que exerce a função de suprir serviços especializados a centros menores em seu entorno, especialmente os serviços ofertados para o setor produtivo regional, que exigem uma escala urbana mínima relativamente elevada. De acordo com Henderson (1974), a explicação para diferentes tamanhos de cidades em um sistema urbano deve-se ao papel de cada uma delas na produção de bens e serviços. À medida que as economias externas de escala são específicas de atividades particulares, cada cidade tende a se especializar em poucas atividades, que requerem, por sua vez, escalas mínimas de tamanho urbano eficientes e diferenciadas. Assim, uma cidade têxtil não precisa ter uma dimensão além da necessária para abarcar um aglomerado de plantas de fiação e tecelagem, enquanto uma cidade com função de centro financeiro deve ser grande o suficiente para absorver o conjunto das operações bancárias de um país. (FUJITA et al., 1999, p. 20).

A teoria do lugar central, vista sob esse aspecto, enseja claramente uma concepção de "área de mercado", a ser polarizada pelo centro urbano de maior população e densidade na oferta de serviços. A teoria da base exportadora, por sua vez, estabelece os nexos de trocas em âmbito inter-regional. 
Em razão do poder de centralidade dos serviços, o nível de terciarização de uma localidade é o melhor indicador de sua capacidade de polarização. (LEMOS, 1991). A concentração das atividades residenciais, próprias do setor de serviços, é que irá diferenciar uma base exportadora de bens de um lugar cujo mercado interno adquiriu o tamanho necessário ao desenvolvimento de algumas atividades terciárias não ubíquas, em decorrência dos elevados requisitos de escala de aglomeração urbana.

Ao adquirir um determinado porte, esse lugar de maior densidade urbana tende a se constituir em centro de consumo coletivo, que tende a atrair um fluxo de pessoas se deslocando até ele em busca de atividades especializadas não exportáveis, dadas as suas características de intransportabilidade. Esse fluxo de pessoas origina-se de lugares de menor escala urbana, que constituem as áreas de influência ou entorno do lugar central. Por causa de sua estrutura produtiva, estas áreas urbanas, ou regióes, são caracterizadas como bases exportadoras. Por outro lado, na ausência dos nexos de trocas necessários à integração intra e inter-regional, as regiões podem ser caracterizadas como enclaves administrativos, ou simplesmente "vazios" econômicos.

Perroux (1961) contribui para desenvolver o conceito de polarização de um lugar central, subjacente à idéia de região. Ele define espaço por sua natureza "econômica" e posição de força ou dominância. Ou seja, a hierarquia urbana é replicada no espaço como um processo de dominação econômica entre regiões, que resulta na existência de localidades-pólos e áreas dominadas, embora sua noção de espaço econômico não seja necessariamente contínuo.

Diante dessas proposições teóricas, sumariamente expostas acima, coloca-se o seguinte problema: uma vez que a polarização se caracteriza pela dinâmica específica de um setor, o terciário, e que a área de influência de um pólo está relacionada a um fluxo de trocas (o deslocamento de mercadorias e de pessoas em busca de serviços), como determinar, dentro de um dado conjunto de informações estatísticas disponíveis, um perfil hierárquico de regiões econômicas? Por outro lado, como contemplar, neste conjunto de informações, o fluxo de trocas decorrentes das exportações inter-regionais, de forma a garantir a natureza de economia aberta das regióes? 
É na tentativa de solucionar parte dessas questões que este estudo objetiva aplicar o modelo gravitacional usado por Isard e Bramahall (1960), que visa definir a área de influência dos principais pólos econômicos de um macroespaço geográfico, em geral definido como um país. Desta forma, o modelo gravitacional permite a definição de um esboço da área de interação de um pólo, próximo à idéia de área de mercado, levando em conta o poder de atração determinado positivamente pela intensidade das trocas e negativamente pela distância geográfica, esta última refletida economicamente no custo de transporte por unidade do produto transportado.

\section{A METODOLOGLA DE REGIONALIZAÇÃO}

O procedimento inicial da regionalização foi a definição de um critério para a hierarquização dos pólos econômicos do País, segundo três escalas: micro, meso e macropólos. Para tal, adotamos as Microrregiões Geográficas (MRGs) como unidades espaciais básicas, para a elaboração de um Índice de Terciarização, calculado com base na massa de rendimentos dos setores agropecuário, industrial e de serviços lastreados nos microdados do Censo Demográfico de 1991 do IBGE. Em razão dos objetivos do estudo e da confiabilidade das informações, o Censo Demográfico mostrou-se a melhor fonte de informação disponível. ${ }^{3}$

Com base no total de rendimentos por microrregião, o Índice de Terciarização - It foi calculado com base na fórmula proposta por Lemos (1991):

ÍNDICE DE TERCIARIZAÇÃO

$$
I=\frac{M}{(M I+M+M+M)}
$$

3 A alternativa de utilização de informações mais atualizadas da RAIS, do Ministério do Trabalho, não é adequada, pois apenas as pessoas jurídicas são obrigadas a preenchê-la. Com isso, o setor agrícola e de serviços ficam subestimados na amostra, já que os produtores rurais, em sua grande maioria, não constituem pessoa jurídica, ocorrendo o mesmo com o trabalho por conta própria e/ou sem carteira. Assim, o banco de dados construído para essa análise partiu do levantamento do "valor bruto do rendimento da ocupação principal" do Censo Demográfico, agrupados pelo "código da atividade", como substituto da renda setorial das microrregióes geográficas brasileiras, em razão da inexistência de dados sobre o valor bruto e agregado da produção. 
Ms = massa de rendimentos do setor serviços

$\mathrm{Ma}=$ massa de rendimentos do setor agropecuário

$\mathrm{Mi}=$ massa de rendimentos do setor industrial

$\mathrm{Mn}=$ massa de rendimentos não classificada.

Assim, It indica, por um lado, a capacidade de carregamento do conjunto das atividades econômicas de uma região pelos serviços ofertados especificamente por uma dada localidade, o pólo. Na terminologia de Christaller (1966) [1933], trata-se de "bens centrais", produzidos apenas no "lugar central de ordem superior", ou seja, não produzidos nas localidades de "ordem inferior". A idéia de "capacidade de carregamento" deste lugar central seria medido por sua capacidade de ofertar serviços necessários para atender à demanda do conjunto das atividades produtivas de toda a região. Assim, um pólo com maior capacidade de oferta de serviços possui maior capacidade de "carregamento" ou sustentação da produção regional de bens, quer sejam bens agrícolas, minerais ou industriais. Por outro lado, o It é um índice da capacidade de transbordamento da oferta desses serviços para outras localidades, que são atraídas por esse "lugar central de ordem superior" para o consumo de seus serviços. Ou seja, a "capacidade de transbordamento" mede a capacidade da oferta de serviços de atrair demanda no espaço, enquanto a "capacidade de carregamento" mede a capacidade da oferta de sustentar a demanda regional.

O cálculo de It para todas as microrregiões possibilita o estabelecimento de uma hierarquia funcional inter-regional, baseada na escala urbana dessas áreas, dada pela dupla capacidade de carregamento e transbordamento de seus serviços. No caso de uma cidade como São Paulo, por exemplo, especializada em serviços financeiros, o transbordamento de seus serviços especializados atinge todo o território nacional, já que não são reproduzíveis em outros centros urbanos, em decorrência da escala mínima eficiente. Por outro lado, a hierarquia resultante indicou distorções em regiões com poucas atividades produtoras de bens (industriais e agrícolas), o que resultou em um pequeno denominador e um elevado $I t$, resultantes dos serviços tipicamente residenciais de ordem inferior, como os serviços básicos de educação, de saúde e alimentares. Isto é típico de cidades dormitórios ou 
áreas economicamente vazias, como, por exemplo, a MRG de Fernando de Noronha.

A solução encontrada para contornar essa dificuldade metodológica foi obter um indicador de terciarização com lastro produtivo, ou seja, que expressa não apenas uma elevada oferta de atividades terciárias, mas também o volume de atividades diretamente produtivas.

Para isto criamos um fator de ponderação para o índice de terciarização puro, baseado nos rendimentos totais da MRG em questão. Em razão da magnitude e amplitude dos valores observados, utilizamos um conversor logarítmico de escala que atribui o fator 0,95 , denominado referencial, à maior massa de rendimentos. Como se trata de escalas relativas de tamanho, este referencial poderia ser diferente sem alterar os resultados, desde que se atenda à restrição de ser menor do que 1 e maior do que zero e se busque, sempre, a ampliação do espectro do $M t_{c}$ objetivando-se, com isso, ressaltar e visualizar as diferenças entre os centros urbanos. O cálculo para as demais microrregiões considera a proporção logarítmica inversa representada pela expressão abaixo.

MASSA DE RENDIMENTOS TOTAL CONVERTIDA

$$
M t_{c}=1-e^{-\left(\frac{-\ln (0.05) *}{M t_{r f}} M t_{i}\right)}
$$

$M t_{c}=$ massa de rendimentos total convertida

$M t_{\text {ref }}=$ massa de rendimentos total de referência

$M t_{i}=$ massa de rendimentos total da região

Obtém-se, a partir daí, o Índice de Terciarização Ajustado $\left(I t^{*}\right)$ :

$$
I_{*}=\boldsymbol{I} * M_{c}
$$

O Gráfico 1 mostra os espectros da distribuição do Índice de Terciarização Puro (It) e do Índice de Terciarização Ajustado (It $)$ para todas as MRGs. Observa-se que o formato da distribuição do It é decrescente, mas muito oscilante, à medida que descendemos de MRGs com massas de rendimentos 
maiores para as menores, o que reflete as distorções já apontadas do índice puro. Após uma menor variabilidade da calda superior da distribuição (It $\geq 0,5$, com valor máximo de 0,86 para Brasília), o restante da distribuição apresenta forte variabilidade, com MRGs que possuem massas de rendimentos acima da média, mas com baixos índices de terciarização $(I t \leq 0,4)$, até o extremo oposto de MRGs na calda inferior da distribuição, com pequenas massas de rendimentos e índices de terciarização relativamente elevados (It $\geq 0,4)$. O formato da distribuição do $I t^{*}$, por sua vez, é uma curva de ajuste côncava em relação à origem, iniciando pelo valores observados máximos de 0,65 e 0,63 (Rio de Janeiro e São Paulo, respectivamente ${ }^{4}$ ), tangenciando o eixo vertical, seguido de uma segmentação posterior dos valores observados, em que a microrregião subseqüente (Belo Horizonte) apresenta índice acentuadamente menor, de valor igual a 0,27 . O espectro entre este último valor observado até o valor de 0.094 (Manaus) corresponde a um segmento da curva bem delimitado, antes de sua passagem pela origem em direção ao eixo horizontal. Após passar pela origem, a curva aproxima-se progressivamente do eixo horizontal até tangenciá-lo, quando se tem um segmento final de MRGs com valores observados mínimos, próximos de zero.

Efetuados os cálculos, estabeleceu-se um piso, situado próximo a 0,1 , para a seleção dos principais pólos, denominados macropólos. O critério para este piso baseou-se no ponto de inflexão da distribuição de frequiência de $I t^{*}$. $\mathrm{O}$ formato da distribuição apresenta clara inflexão depois da microrregião de Manaus $(0,094)$, excluídas as MRGs com elevado $I t^{*}$, mas contíguas a uma microrregião de $I t^{*}$ ainda maior. $\mathrm{O}$ caso das MRGs contíguas à MRG de São Paulo é o mais notório. Na distribuição sem "expurgos”, Santos e Osasco, por exemplo, aparecem em posição superior a Goiânia, Belém e Manaus (nessa ordem), mas são excluídas em razão da contigüidade geográfica e da complementaridade econômica com São Paulo. Assim, após o "expurgo" das MRGs contíguas, a distribuição apresenta segmentos com agrupamentos de MRGs bem delimitados. Em um patamar superior, no plano vertical, estão três agrupamentos. O primeiro, constituído pelas duas MRGs primazes, São Paulo e Rio de Janeiro (no espectro de valores de 0,6), seguido pelo segundo, compreendido por Belo Horizonte, Porto Alegre, Salvador, Curitiba e Brasília, que apresenta uma significativa segmentação

4 Duas razões explicam i maior $\mathrm{It}^{*}$ do Rio em relação a São Paulo: o nível mais do que proporcional da participação dos serviços públicos no Rio (herança de ex-capital federal) e o nível também desproporcional da indústria em São Paulo (tradição de grande cidade industrial). 
em relação ao agrupamento 1 (espectro de valores em torno de 0,2 ) e o terceiro, com Fortaleza, Goiânia, Belém e Manaus (espectro em torno de $0,1)$. Neste ponto, observa-se grande inflexão da curva ao passar próxima da origem, como ilustra a Figura 1, a partir da qual a distribuição é contínua e decrescente, tendendo ao tangenciamento em relação ao eixo horizontal. $\mathrm{Na}$ verdade, se excluirmos os dois centros primazes, o coeficiente de variação ( $\mathrm{CV}$ ), razão do desvio padrão pela média, das $10 \mathrm{MRG}$ do segmento da distribuição dos agrupamentos (2) e (3) é bem inferior ao CV de toda a distribuição. Observa-se, também, a existência de patamar intermediário de valores observados de $I t^{*}$, constituídos pelas MRGs do segmento de contorno da curva entre os eixos vertical e horizontal. As MRGs contidas neste segmento são definidas como os 87 "mesopólos” da regionalização.

\section{FIGURA 1 - It E CURVAS DE AJUSTE}

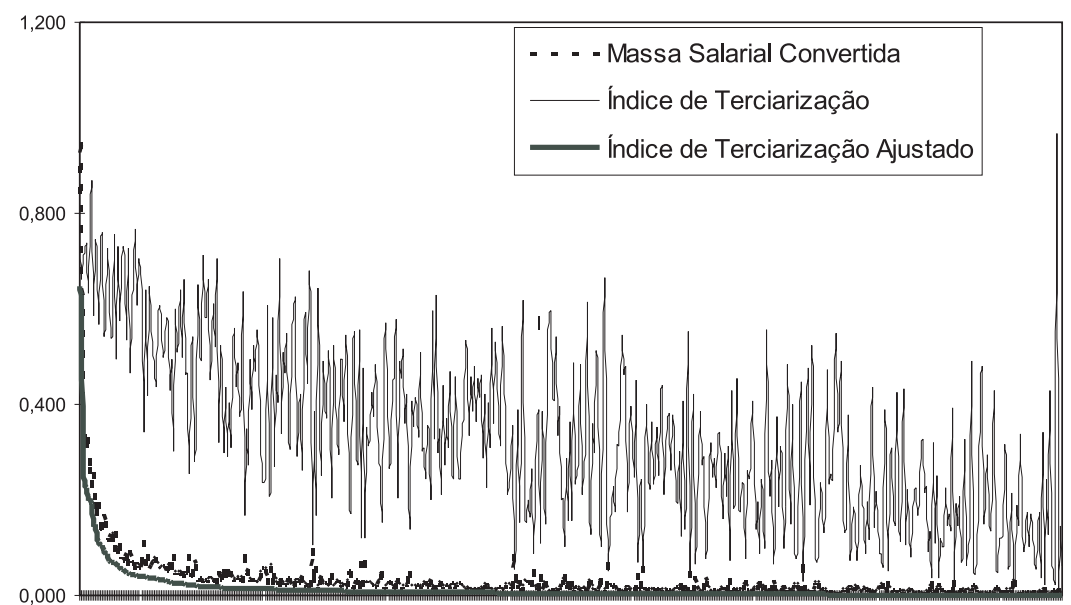

As doze MRGs dos três primeiros agrupamentos foram, portanto, hierarquizadas pelo Índice de Terciarização Ajustado, conforme a Tabela 1. Dadas as características peculiares de Brasília, como capital federal (poucas atividades da esfera produtiva e muitos serviços ligados à administração pública e serviços pessoais), a aglomeração urbana relativamente pequena de Goiânia e a relativa proximidade geográfica das duas cidades, decidimos tratá-las como um macropólo conjunto no processo de polarização. ${ }^{5}$

5 Rigorosamente, Cuiabá deveria compor a multipolarização do Centro-Oeste, sendo, no entanto, excluída por dificuldades metodológicas. 
É interessante observar que existe coincidência entre os macropólos selecionados e as metrópoles que encabeçam os sistemas urbano-regionais, identificados no estudo IPEA/IBGE/NESUR (1999, p. 341). As diferenças residem nos resultados finais, dados os objetivos específicos dos dois trabalhos. Ao contrário do nosso trabalho, aquele estudo não pretende realizar uma regionalização econômica do País, com contornos geográficos bem estabelecidos e delimitados. Seu objetivo é analisar a rede urbana brasileira, tendo como suporte técnico principal os estudos do IBGE-DEGEO, Rede de influência das cidades, 1993, Aglomerações urbanas para fins estatístico e Tipologia dos municípios brasileiros. Nossa pretensão, por outro lado, é de fato produzir uma regionalização econômica em sentido estrito, inclusive desconsiderando a divisão político-administrativa da federação brasileira. Usamos, para isto, uma metodologia de regionalização e procuramos deixar o modelo falar por si mesmo, com a menor utilização possível de soluções ad hoc, as quais procuramos explicitar.

\section{TABELA I - HIERARQUIA DOS MACROPÓLOS SELECIONADOS SE- GUNDO O ÍNDICE DE TERCIARIZACÃO AJUSTADO}

\begin{tabular}{|c|c|c|c|c|c|c|c|c|}
\hline \multirow[t]{3}{*}{ MRG } & \multicolumn{5}{|c|}{ Massa de Rendimentos } & \multirow{3}{*}{$\begin{array}{c}\text { Mt c }= \\
\text { Massa } \\
\text { Total } \\
\text { Convertida }\end{array}$} & \multirow{3}{*}{$\begin{array}{c}\text { IT }= \\
\text { Índice de } \\
\text { Terciari- } \\
\text { zação }\end{array}$} & \multirow{2}{*}{$\begin{array}{c}\mathrm{iT} \mathrm{T}^{*}= \\
\text { Índice de } \\
\text { Terciari- } \\
\text { zação }\end{array}$} \\
\hline & Agricultura & Industria & Serviços & N.Class. & Total & & & \\
\hline & & & & & & & & Ajustado \\
\hline RIO DE JANEIRO & 167,432 & $2,596,489$ & $9,800,662$ & 132,403 & $12,696,985$ & 0.8394 & 0.77 & 0.648 \\
\hline SAO PAULO & 238,977 & $6,386,060$ & $13,784,504$ & 388,336 & $20,797,878$ & 0.9500 & 0.66 & 0.630 \\
\hline BELO HORIZONTE & 88,630 & 867,648 & $2,344,253$ & 25,162 & $3,325,693$ & 0.3806 & 0.70 & 0.268 \\
\hline PORTO ALEGRE & 69,691 & 705,563 & $1,984,785$ & 11,092 & $2,771,131$ & 0.3291 & 0.72 & 0.236 \\
\hline SALVADOR & 56,270 & 593,270 & $1,882,515$ & 28,070 & $2,560,125$ & 0.3084 & 0.74 & 0.227 \\
\hline CURITIBA & 392,077 & 609,634 & $1,749,539$ & 21,668 & $2,772,917$ & 0.3293 & 0.63 & 0.208 \\
\hline RECIFE & 53,803 & 436,075 & $1,656,463$ & 15,924 & $2,162,265$ & 0.2676 & 0.77 & 0.205 \\
\hline BRASILIA & 49,433 & 196,198 & $1,526,488$ & 2,633 & $1,774,752$ & 0.2256 & 0.86 & 0.194 \\
\hline FORTALEZA & 81,512 & 295,356 & $1,143,008$ & 11,351 & $1,531,227$ & 0.1979 & 0.75 & 0.148 \\
\hline GOIANIA & 97,709 & 197,122 & 790,180 & 6,076 & $1,091,087$ & 0.1454 & 0.72 & 0.105 \\
\hline BELEM & 59,677 & 186,147 & 782,337 & 6,050 & $1,034,211$ & 0.1384 & 0.76 & 0.105 \\
\hline MANAUS & 236,507 & 331,066 & 715,519 & 24,397 & $1,307,490$ & 0.1717 & 0.55 & 0.094 \\
\hline
\end{tabular}

Fonte: Censo Demográfico 1991, IBGE (dados originais). 
Definida essa hierarquia, o próximo passo foi a mensuração do Índice Potencial de Interação das demais 546 MRGs do País com os macropólos selecionados, tendo o modelo gravitacional como referência. O cálculo efetuado consiste em estimar a força de atração de uma unidade espacial central (o pólo) perante as demais MRGs, na razão direta do produto de suas massas de rendimentos e na razão inversa do quadrado de suas distâncias. Assim:

ÍNDICE POTENCIAL DE INTERAÇÃO DE DOIS PONTOS NO ESPAÇO

$$
g_{c}=\frac{\sum M_{j}}{d_{j}{ }^{2}}
$$

Onde:

$M t_{i j}=$ somatório das massas de rendimentos totais da região i e j

$d_{i j}=$ distância entre a região i e a região j

Para o cálculo da distância entre as regiões utilizamos a distância geodésica entre os centróides das 557 MRGs brasileiras. O centróide de cada MRG é o seu município de maior população, sendo, para isto, utilizadas as informações de longitude e latitude de sua sede, com base na malha digital municipal de 1991, como mostra o Mapa 1. 


\section{MAPA I - MICRORREGIÓES GEOGRÁFICAS E CENTRÓIDES ${ }^{(1)}$}

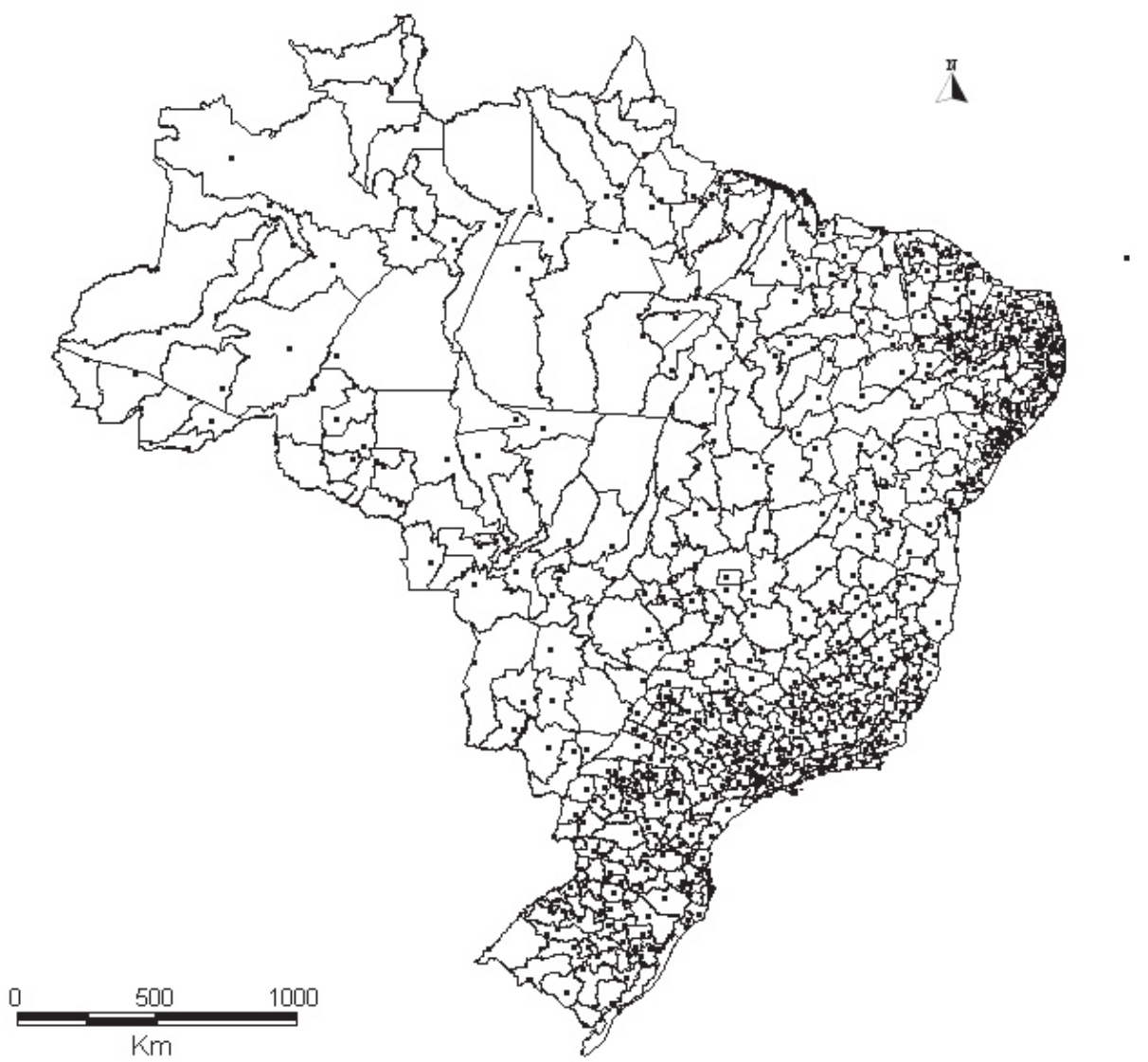

Fonte: IBGE, Divisão Territorial do Brasil, Malha Digital Municipal, 1991.

(1) Município de maior população.

Surgiram dois problemas metodológicos para o cálculo do índice potencial de interação. O primeiro decorre do uso da distância geodésica, ao invés de um substituto do custo de transporte que levasse em conta, diretamente, os atritos espaciais efetivos, como, por exemplo, a distância por transporte terrestre. A dificuldade está na ausência de dados confiáveis para o conjunto da rede de transportes que interliga as 557 MRGs, o que torna qualquer estimativa deste tipo sujeita a maiores distorções do que a distância geodésica. O possível viés deste procedimento decorre das grandes diferenças na qualidade e extensão da infra-estrutura de transportes na rede urbana brasileira. Isto resulta em diferenças do custo unitário de transporte entre dois 
pontos no espaço. Se esses dois pontos forem, por exemplo, polarizadores potenciais, que possuam a mesma distância e mesmo tamanho econômico em relação a um ponto polarizável, aquele com melhor rede vinculada de transportes e, assim, menor custo unitário, será favorecido na capacidade de polarização, pois as atividades econômicas, nesse caso, localizam-se segundo o caso clássico weberiano de localização orientada pelo custo de transporte. ${ }^{6}$ (LEME, 1982). É possível, dessa forma, que os pólos mais periféricos à rede de transportes sejam prejudicados, em especial na escala de pequenos números dos pólos mesorregionais. No caso das regióes economicamente vazias, é possível que o uso da distância geodésica seja neutro em termos de resultado de polarização, já que as deficiências da rede de transportes são generalizadas para todos os pontos polarizadores potenciais dessas áreas.

O segundo problema é a inexistência de informações quantitativas acerca do fluxo de mercadorias e da procura de serviços no Brasil, problema este recorrente em estudos regionais, como atesta o estudo IPEA/IBGE/NESUR (1999). A solução encontrada foi aplicar o modelo gravitacional, tendo como numerador uma variável de estoque como substituta da variável de fluxo, criando-se um índice potencial de interação, já que não estamos medindo interações efetivas via fluxo de fatores e bens. Utilizamos, para isto, a variável de rendimentos do Censo Demográfico de 1991, cuja magnitude irá representar o potencial de área de mercado de uma região, dado pela área de influência espacial das mercadorias e serviços entre dois pontos no espaço.

Cabe salientar que, neste caso, seguimos a convenção dos modelos gravitacionais tradicionais ao usarmos o quadrado da distância como coeficiente padrão de atrito da distância. (ISARD \& BRAMAHALL, 1960). Como o que se pretende preencher é a ausência do custo de transporte, estes autores já estavam atentos para as dificuldades do uso do quadrado da distância, emprestado diretamente dos modelos gravitacionais da física. A alternativa sugerida seria estimar, estaticamente, o expoente $(\beta)$, de modo a especificar

6 Ceteris paribus, os demais fatores locacionais. 
uma equação que incorporasse variáveis explicativas para as diferenças de atrito espacial entre os pontos no espaço. No entanto, as limitações de dados municipais para todo o País poderiam levar a um erro estatístico considerável e comprometer mais ainda os resultados. A não utilização de qualquer expoente da distância, outra alternativa, seria ainda pior, pois sabemos que a força de atração no espaço não é linearmente decrescente, já que os efeitos positivos dos retornos crescentes de escala em razão de economias de aglomeração são extremamente sensíveis à distância. Caso fosse possível a estimação de $\beta$, as diferenças de resultado poderiam ser maiores para o sistema de polarização mesorregional do que para o macrorregional, em razão da lógica dos grandes números. Como salientado na questão anterior da distância geodésica, espera-se, também, que o uso do quadrado da distância em substituição ao $\beta$, estimado em casos de diferenças de infra-estrutura de transportes, enviesem os resultados a favor dos pólos mais periféricos, em especial na escala de pequenos números dos pólos mesorregionais.

Ilustramos, no Mapa 2, a forma de cálculo do índice potencial de interação $\left(\operatorname{Ig}_{c}\right)$ de todos os 11 macropólos selecionados para uma microrregião polarizável qualquer, como Foz do Iguaçu, que, como as demais 544 MRGs, é candidata potencial a ser polarizada por um macropólo. Mesmo apresentando interação econômica com todos eles, a MRG será polarizada pelo macropólo de maior interação econômica, ou seja, a MRG será polarizada pelo macropólo de maior $\left(I_{c}\right)$, respeitada a restrição de contigüidade geográfica, a qual não limita, porém, a extensão geográfica da polarização. 


\section{MAPA 2 - EXEMPLO DE CÁLCULO DO Ig PARA OS 11 MACROPÓLOS}

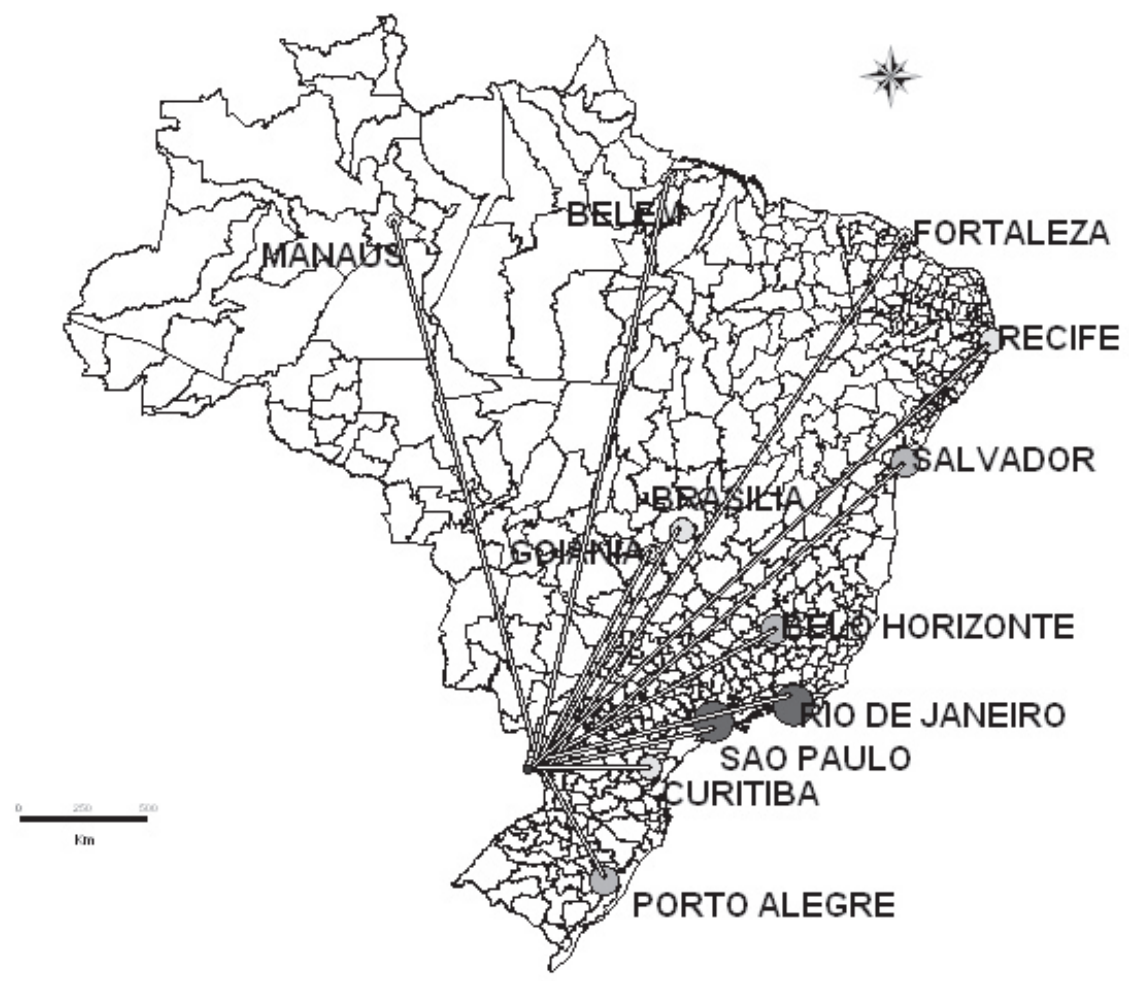

O procedimento para a identificação das áreas de influência segue o critério de hierarquia econômica espacial, ou seja, cada macropólo cria sua macrorregião pela atração de um conjunto de microrregiões, que, por sua vez, serão subpolarizadas no interior da macrorregião pelos mesopólos, que atraem um conjunto de microrregiões para constituírem uma mesorregião. Houve, portanto, duas rodadas de cálculo, a primeira para delimitar geograficamente as 11 macrorregióes e a segunda para delimitar as 87 mesorregiões que estão contidas no "campo de forças" interno das macrorregiões.

Finalmente, a regionalização, obtida da aplicação desse modelo, incorpora em seus resultados uma análise da fricção espacial, como um refinamento ao desenho inicial proposto. A representação cartográfica de diversas seleções pelo Sistema de Informações Geográficas - SIG permite uma avaliação comparativa dos resultados, identificando, de maneira precisa, quais MRGs irão compor determinada região e, principalmente, quais se situam nos 
seus limites estabelecidos pela aplicação do modelo. É sobre esses limites que se dá o refinamento dos resultados. A atribuição da polarização se dá pela comparação numérica de índices. Ocorre que, em muitos casos, há uma tênue e insignificante diferença entre os índices. Algumas vezes existe a impossibilidade da ocorrência de um fluxo significativo de mercadorias e pessoas na direção do pólo de maior índice, em virtude da precariedade das estradas ou simplesmente por sua inexistência.

Essa tarefa visa corrigir distorções claramente verificadas nos limites das regiões que porventura ocorram em uma aplicação acrítica do modelo. O exemplo mais contundente deste problema é quando o resultado da aplicação do modelo define a polarização potencial de uma MRG que, no entanto, possui acesso precário, ou inexistente, à região pólo. Em outro caso limite, o modelo pode estar determinando polarização contrária ao que é conhecido acerca do escoamento do fluxo de produção de um lugar, observações essas verificadas principalmente nos casos das bases exportadoras agropecuárias. Em uma outra situação estão as MRGs cuja base econômica seja inexpressiva. Neste caso, a polarização existe somente dentro de uma lógica político-administrativa. Em todos esses casos, a revisão dos resultados foi feita tendo como referência os resultados do REGIC (1993), ${ }^{7}$ utilizandose, secundariamente, critérios qualitativos com vistas ao aperfeiçoamento dos resultados.

\section{A NOVA CONFIGURAÇÃO REGIONAL BRASILEIRA}

Dos doze macropólos selecionados da Tabela 1 , foram identificadas onze áreas de polarização, dado que o Centro-Oeste é uma área multipolarizada por Brasília e Goiânia. Esses macropólos estão posicionados no topo da hierarquia regional brasileira, sob a ótica da área de acesso a mercados regionais que cada pólo pode dominar no âmbito geográfico da economia

7 A pesquisa do IBGE, Regióes de Influência das Cidades (1993), que qualifica a intensidade dos fluxos entre as cidades brasileiras como Muito Forte (4), Forte (3), Média (2) e Fraca (1). 
nacional. O volume das massas de rendimentos de São Paulo e Rio de Janeiro, comparativamente às demais, torna-os, indiscutivelmente, pólos nacionais. A área de influência que o modelo atribui a eles é o território nacional. Para a determinação da área de influência dos demais macropólos foi necessário realizar uma segunda rodada do algoritmo de modo a delimitar seus contornos. O Mapa 3 apresenta o resultado-síntese da regionalização econômica do País.

Salta aos olhos o "rateio" do espaço regional brasileiro pelos onze macropólos. Observa-se que Estados inteiros "desaparecem" literalmente do mapa, como Espírito Santo e Santa Catarina. No caso de Minas, o pólo de Belo Horizonte possui uma capacidade limitada de polarização sobre o espaço geográfico mineiro, "perdendo" as regiões de maior peso econômico e preservando, além de seu entorno industrial, regiões menos desenvolvidas e de subsistência. O Triângulo Mineiro e a parte "rica" do Sul de Minas vão para São Paulo. O Rio incorpora a Zona da Mata Mineira e o restante do Sul do Estado, enquanto o Noroeste Mineiro é incorporado por Brasília-Goiânia. O Centro-Oeste perde o Mato Grosso do Sul e o Sudoeste de Goiás, incorporados, como o Triângulo Mineiro, pela expansão paulista para o oeste brasileiro. No caso do Nordeste, os pólos de Salvador, Recife, Fortaleza e Belém incorporam as demais capitais de Estado da região como áreas de influência, graças ao poder relativamente pequeno de interação e o baixo índice de terceirização destas capitais de menor porte. Manaus, por sua vez, polariza aparentemente uma extensa área geográfica, mas economicamente vazia. O procedimento para a identificação das áreas de influência segue o critério de hierarquia econômica estabelecido. Assim, cada macropólo cria sua macrorregião pela atração de um conjunto de mesorregiões, cujos mesopólos, por sua vez, atraem um conjunto de microrregióes. Os Mapas de 4 a 14 sintetizam os resultados encontrados para as mesorregiões, segundo o macropólo. 


\section{MAPA 3 - OS MACROPÓLOS BRASILEIROS E SUAS ÁREAS DE IN- FLUÊNCIA}

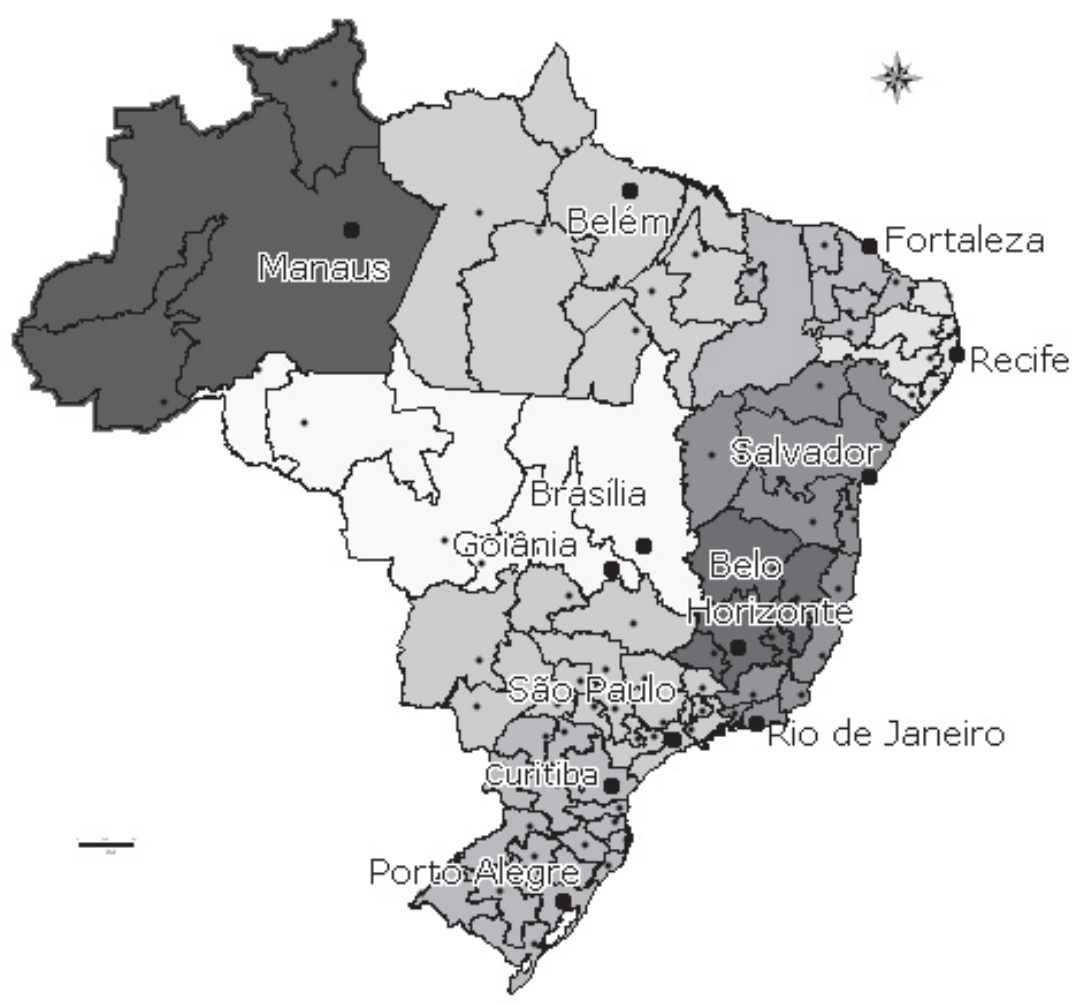

MAPA 4 - MESORREGIÓES POLARIZADAS POR SÃO PAULO

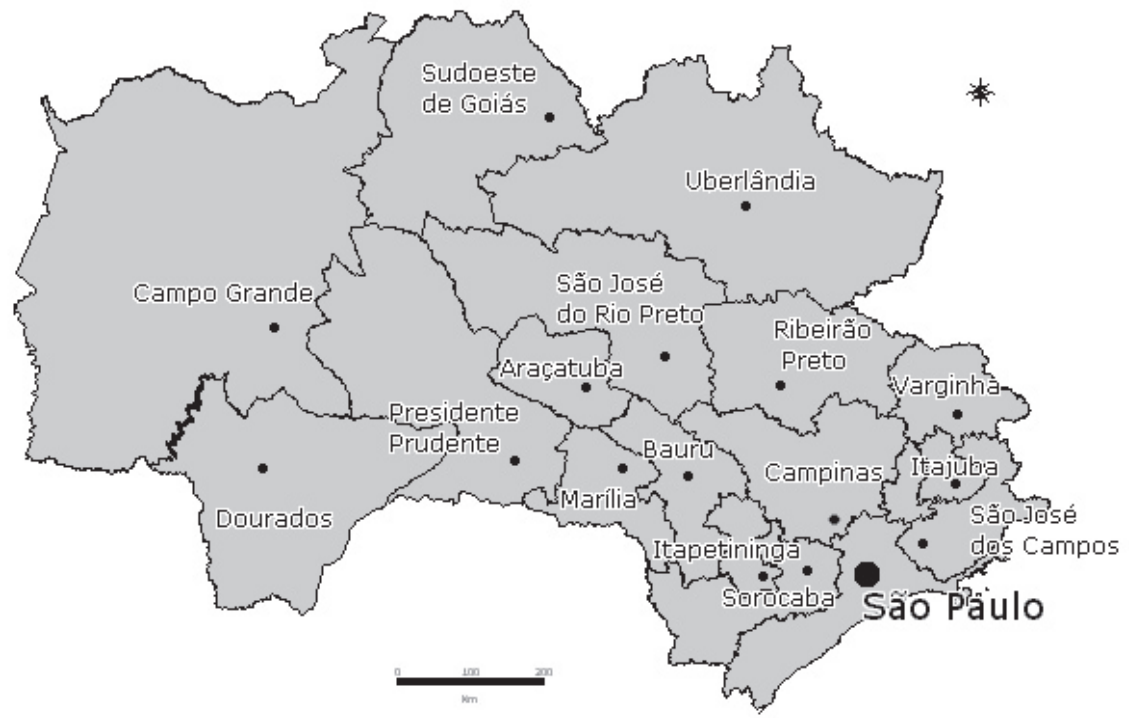

Est. econ., São Paulo, 33(4): 665-700, out-dez 2003 
MAPA 5 - MESORREGIÕES POLARIZADAS PELO RIO DE JANEIRO

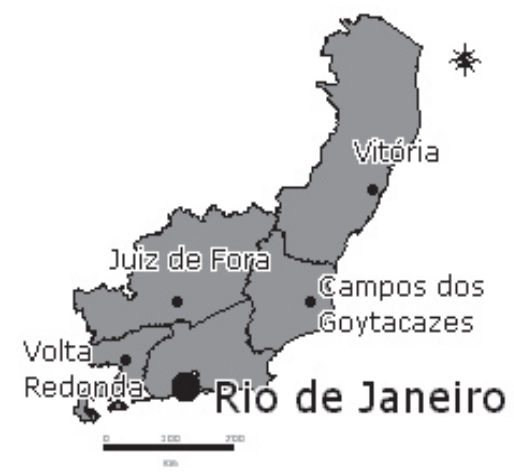

MAPA 6 - MESORREGIÓES POLARIZADAS POR BELO HORIZONTE

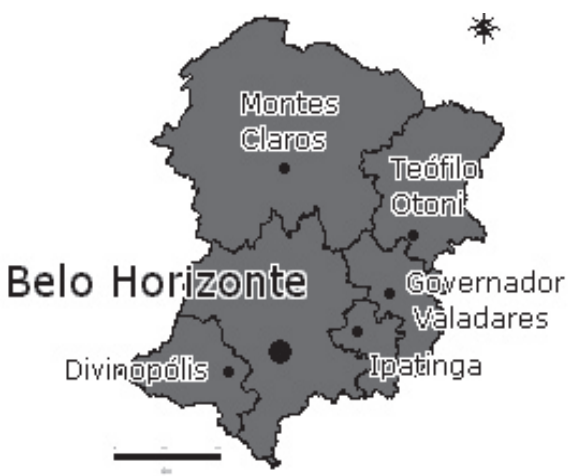

MAPA 7 - MESORREGIÓES POLA- MAPA 8 - MESORREGIÓES POLARIZADAS POR PORTO ALEGRE RIZADAS POR SALVA$D O R$
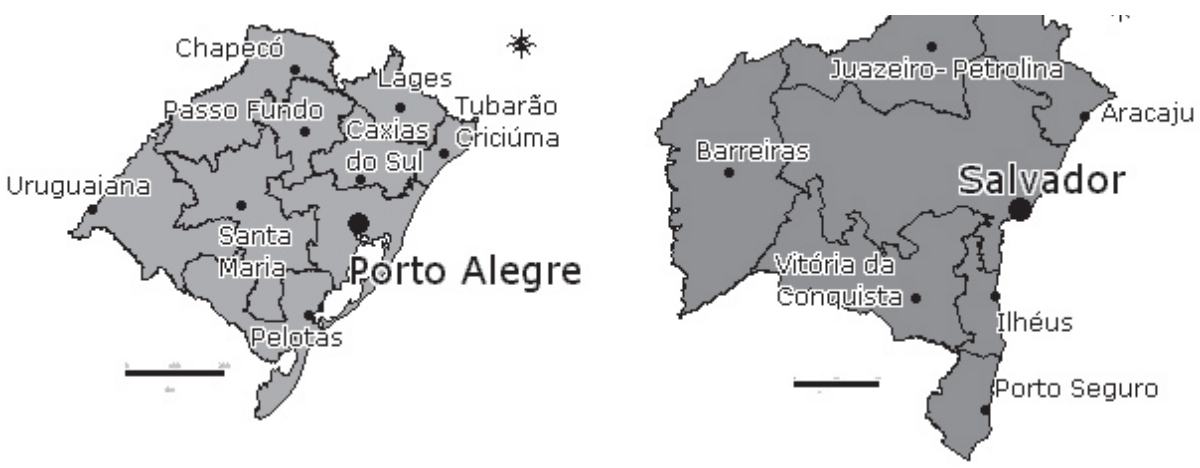

MAPA 9 - MESORREGIÓES POLA- MAPA 10 - MESORREGIÓES PORIZADAS POR CURILARIZADAS NO CENTIBA TRO-OESTE
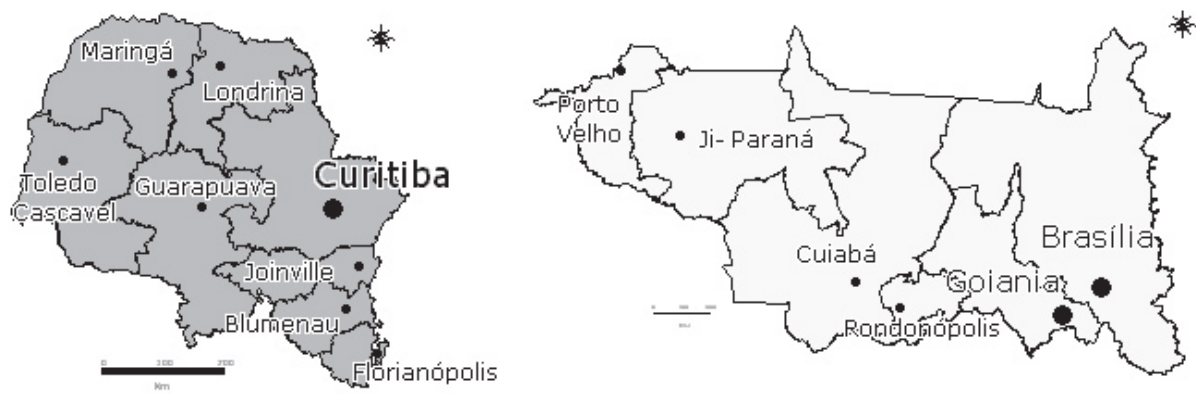
MAPA 11 - MESORREGIÕES POLARIZADAS POR RECIFE

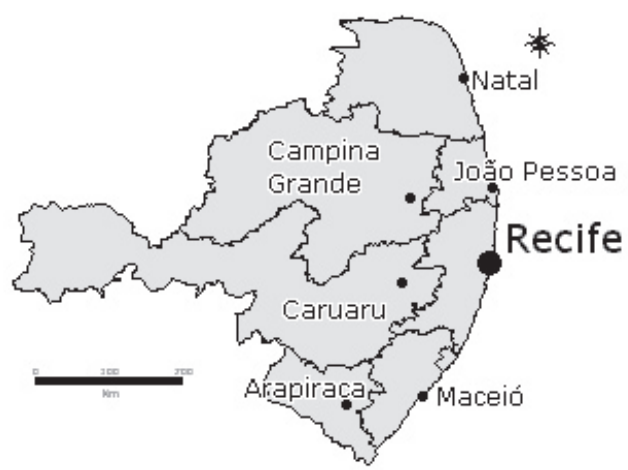

MAPA 13 - MESORREGIÕES POLARIZADAS POR BELÉM

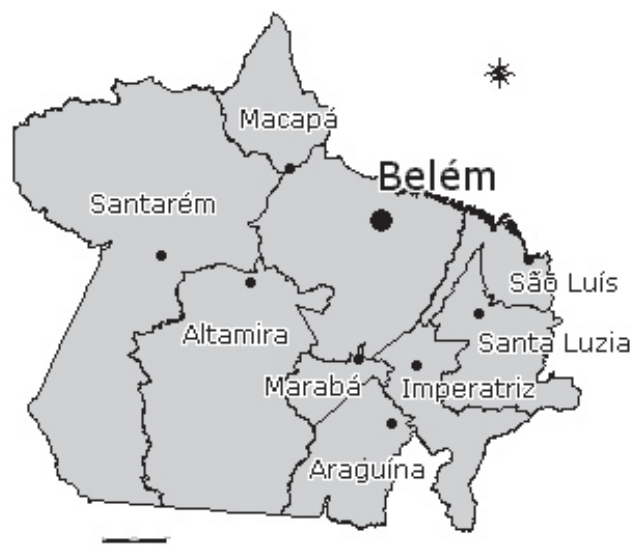

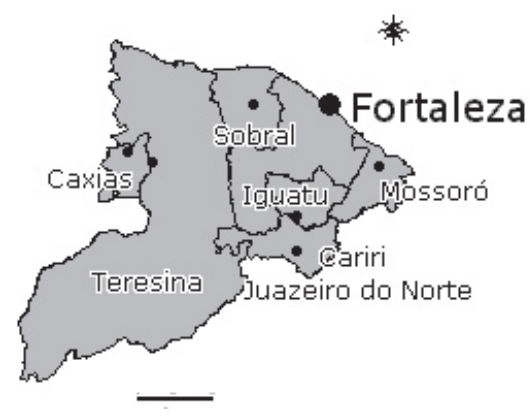

\section{MAPA 12 - MESORREGIÓES POLARIZADAS POR FORTALEZA}

\section{MAPA 14 - MESORREGIÓES POLARIZADAS POR MANAUS}

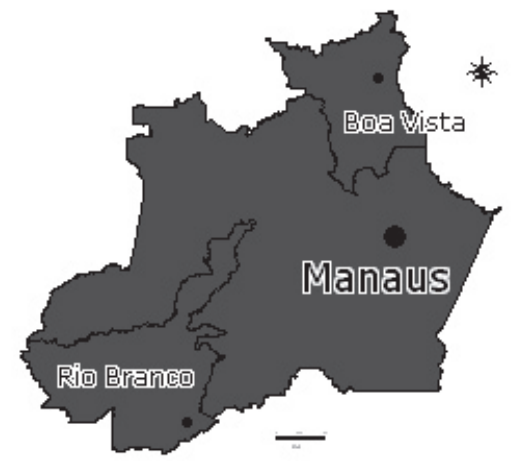

O MAPA 15 apresenta um mapeamento da densidade econômica do Brasil, segundo classes do PIB per capita, com base nas estimativas de PIB municipais para 1996. (ANDRADE \& SERRA, 1996). Os PIB per capita das microrregiões foram agrupados em cinco classes, para o Brasil, pelo critério da média, usando a metodologia de análise de cluster, sendo que o último estrato refere-se à classe de subsistência, definida como estando abaixo da linha de pobreza. (IDH, 1996). Como pode ser observado, 96 
microrregiões brasileiras do Norte e Nordeste encontram-se no estrato de subsistência, enquanto as 120 microrregiões subseqüentes, do quarto estrato, são definidas como sendo de renda baixa. Isto indica um contexto de polarização problemático para essas regiões, dada a ausência de lugares centrais de ordens inferiores no entorno do lugar central de primeira ordem, caracterizando a existência de enclaves, entornos inteiramente de subsistência, ou de regiões relativamente isoladas, pouco integradas economicamente com seu entorno, com baixa densidade populacional e de renda e, subseqüentemente, de pequena demanda local de bens e serviços do lugar central. Algumas manchas escuras, ao norte do País, dão a falsa impressão de densidade, pois são constituídas de extensas áreas geográficas de população rarefeita, onde a atividade econômica exportadora concentra-se em pontos relativamente isolados. Esta situação é contrastante com o contexto de polarização do Sul e Sudeste do País, cujas microrregiões polarizadas estão distribuídas, em sua quase totalidade, entre os dois estratos superiores de renda. No nível superior de densidade intra-regional está o caso de São Paulo e sua área direta de polarização, visualizados no mapa pela faixa mais escura de renda elevada.

Tomando este critério de densidade, procedemos a uma primeira caracterização econômica dos mesopólos e suas áreas de influência. A classificação das mesorregiões baseou-se no critério de densidade do entorno do núcleo urbano centróide de cada meso: enclave (entorno de subsistência e/ou renda baixa); regiões isoladas (entorno de renda baixa e/ou renda média baixa); pólo econômico (entorno predominantemente de renda média alta e elevada). A densidade de fluxo econômico de uma mesorregião deve, portanto, ser significativa para constituir um pólo que expressa a capacidade de integração regional de seu núcleo urbano em relação ao seu entorno e aos fluxos inter-regionais. 


\section{MAPA 15 - DENSIDADE ECONÔMICA SEGUNDO ESTRATOS DO PIB PER CAPITA}

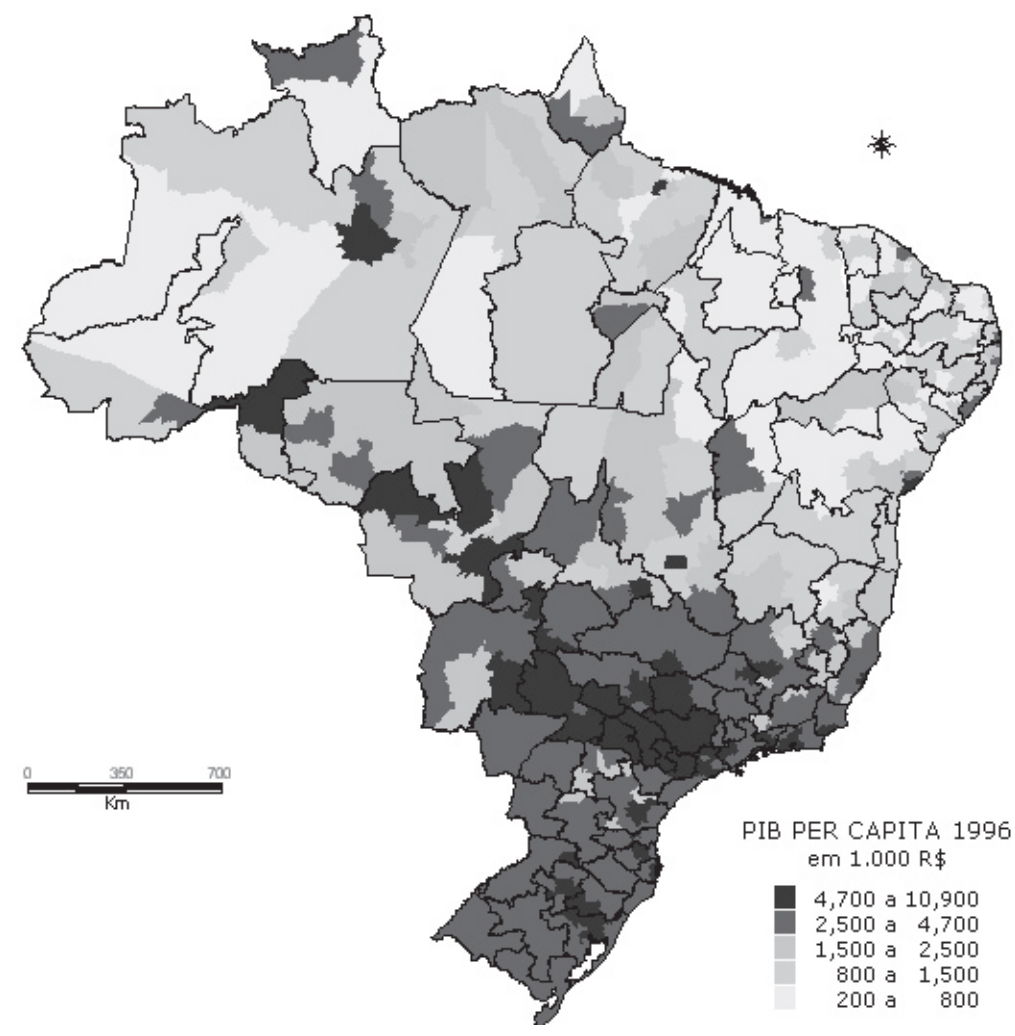

O segundo critério foi o de especialização da região, tendo em vista que a escala econômica do centro urbano depende de sua especialização produtiva ou base exportadora. (FUJITA et al., 1999). Para a identificação da base exportadora utilizamos o Quociente Locacional, que nos fornece um índice de especialização regional. (ISARD \& BRAMAHALL, 1960). Adotamos o critério de estratificação pela média relativa aos QL das atividades agropecuárias, indústria extrativa mineral, indústria de transformação e serviços. Assim, as regiões econômicas (enclaves, regiões isoladas e pólos econômicos) foram classificadas como especializadas em uma ou mais destas atividades básicas. Foi feito um refinamento posterior no caso dos serviços, decompostos em ramos para o cálculo do QL, de forma a diferenciar regióes - cujos serviços predominantes sejam ligados à sua mera função de sede político-administrativa - daquelas em que os serviços cumprem o papel de alavancagem da base exportadora regional. Neste sentido, foram identifica- 
das algumas regiões turísticas - como Rio de Janeiro e Fortaleza - e um pólo financeiro - São Paulo - que integra sua base industrial com sua função de centro financeiro nacional. Os resultados da caracterização econômica das mesorregiões estão apresentados no Quadro 1 e no Mapa 16.

Observa-se a contigüidade das áreas de maior densidade econômica, caracterizadas como pólos industriais e/ou agropecuários, concentradas no Centro-Sul e organizadas a partir da faixa escura do macropólo nacional de São Paulo. As mesorregiões, caracterizadas como pólos industriais, concentram-se na faixa vermelha contígua entre Porto Alegre e Belo Horizonte, que aproximadamente coincide, em seus contornos geográficos, com o polígono industrial identificado por Diniz (1993). Ao longo do polígono situado a oeste encontra-se a extensa faixa verde dos pólos agropecuários das mesorregiões do oeste sulino até as mesorregiões do Centro-Oeste. Este conjunto representa o núcleo duro do desenvolvimento regional brasileiro. A forte integração produtiva entre a base agropecuária e indústria se manifesta, em geral, na sede do pólo urbano das mesorregióes classificadas como agropecuárias, as quais desenvolvem o núcleo industrial integrado à base agropecuária, como exemplificam os casos de áreas de influência de São Paulo, tais como Uberlândia, no Triângulo Mineiro, São José do Rio Preto, no Noroeste Paulista, Dourados, no Mato Grosso do Sul, e Rondonópolis, no Mato Grosso. Nestas localidades têm havido um adensamento da cadeia produtiva pelo desenvolvimento agroindustrial a jusante e a montante.

O perfil de desenvolvimento regional desigual brasileiro completa-se pela desarticulação econômica de uma vasta área contígua de subsistência, intercalada por pequenas manchas de atividades mercantis, que se inicia no norte de Minas e termina no Nordeste setentrional e Norte do País. Emergem daí mesorregiões caracterizadas como enclaves agropecuários ou extrativos, constituídos por núcleos urbanos "ilhados" por áreas de agricultura de subsistência, uma vez que são incapazes de integrar seu entorno e de criar uma base exportadora para sustentar alguma intensidade dos fluxos de troca inter-regionais. Intercaladas entre as áreas de subsistência, encontram-se regiôes isoladas, industriais, agropecuárias ou extrativas, definidas como áreas que possuem atividades mercantis com alguma capacidade de integração com seu entorno, mas sem estabelecer ligações inter-regionais significativas, ou seja, o poder de polarização dessas regiões é limitado a uma pequena 
área de influência. Manaus tipifica bem o caso da região industrial isolada, enquanto Petrolina-Juazeiro e Aracaju exemplificam, respectivamente, os casos de regiões agropecuárias e extrativas isoladas. Os denominados pólos econômicos do Norte e Nordeste possuem características particulares. Como são pólos metropolitanos, sedes de macrorregiões, possuem densidade urbana capaz de integrar o entorno imediato, além do poder de polarização de uma região isolada, ao mesmo tempo que o entorno mais distante é desarticulado, em geral com características de subsistência. No caso dos dois pólos industriais nordestinos, Salvador e Recife, esta capacidade integradora é mais significativa vis-à-vis os pólos turísticos e agropecuários de Fortaleza e Belém, respectivamente. Entretanto, estes pólos industriais são geograficamente segmentados e descontínuos em relação ao corredor industrial do Sul-Sudeste, o que dificulta a integração e complementaridade produtiva nordestina com o centro industrial do País.

\section{MAPA 16 - CARACTERIZACÃO DAS REGIÕES ECONÔMICAS E ÁRE- AS DE SUBSISTENNCIA - REGIONALIZAÇÃO 1991}

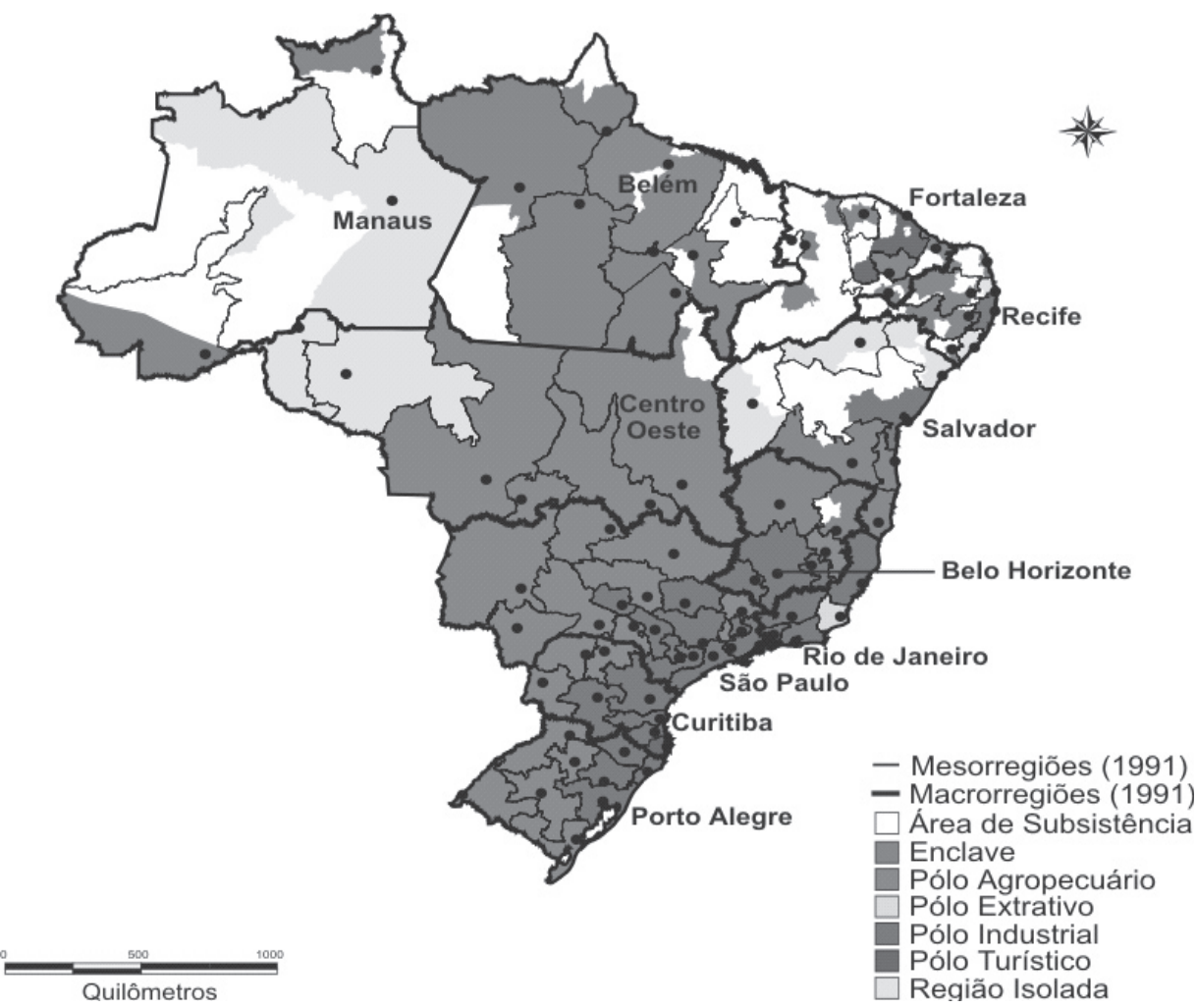


Os resultados do Mapa 16 mostram, portanto, que os macropólos possuem capacidades de polarização efetiva bem diferenciadas, quando se leva em conta a densidade econômica da área potencial de influência, considerando que as áreas de subsistência são vazias economicamente e que os enclaves e regióes isoladas possuem limitada capacidade de integração do entorno vis-à-vis os pólos econômicos. Desta maneira, os contornos da configuração espacial da economia brasileira ficam bem delimitados, evidenciando o forte desequilíbrio regional do País.

Este procedimento possibilita, também, a comparação com os resultados da regionalização econômica de 1980, realizada por Lemos (1991), que pelo fato de não utilizar o modelo gravitacional levou em conta diretamente as "áreas vazias". No caso de 1991, preferimos buscar um "trade-off" que favoreceu a adoção de um modelo mais fechado, em detrimento de um modelo mais aberto, como o de 1980, mas que fica mais susceptível a soluções $a d$ hoc. A análise da diferenciação econômica das regiões possibilita dar um passo à frente e abrir o modelo usado em 1991. Esta abertura do modelo vai refletir a efetiva capacidade de polarização dos centros urbanos regionais. Com o objetivo de comparar os resultados de 1991 com os de 1980, foram realizados os seguintes procedimentos:

1) Georreferenciamento da regionalização de 1980, originalmente não georreferenciada;

2) compatibilização das malhas digitais municipais de 1980 e 1991;

3) compatibilização das microrregiões de 1980 e 1991;

4) compatibilização das nomenclaturas de classificação econômica das regiões;

5) padronização da macropolarização com base em 1991, considerando que as "regiões pólo" de 1980 aproximam-se dos "mesopólos" de 1991, com exceção de São Paulo, e que a regionalização de 1980 não utilizou as definições de macrorregiões e macropólos.

Os resultados originais de 1980 estão apresentados no Mapa 17 e o resultado comparativo no Mapa 18 e Quadro 2. 


\section{MAPA 17 - A REGIONALIZAÇÃO DE 1980}

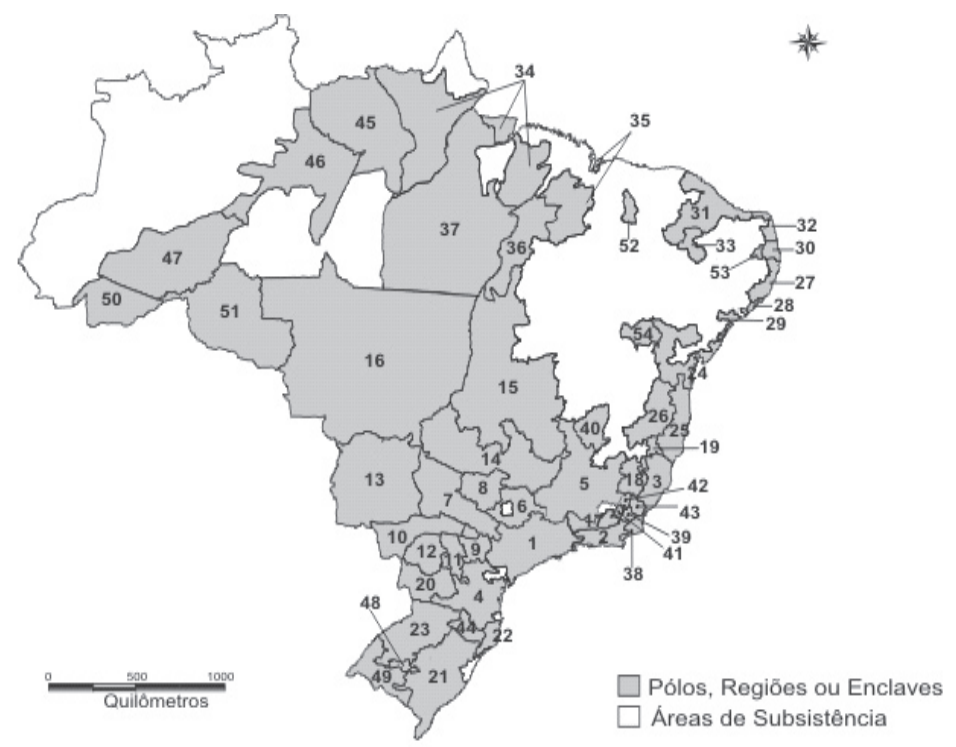

Nome do Pólo, Região ou Enclave

$\begin{array}{ll}1 & \text { São Paulo } \\ 2 & \text { Rio de Janeiro } \\ 3 & \text { Vitória } \\ 4 & \text { Curitiba } \\ 5 & \text { Belo Horizonte } \\ 6 & \text { Ribeirão Preto } \\ 7 & \text { Bauru } \\ 8 & \text { São José do Rio Preto } \\ 9 & \text { Ourinhos } \\ 10 & \text { Presidente Prudente } \\ 11 & \text { Londrina } \\ 12 & \text { Maringá } \\ 13 & \text { Campo Grande } \\ 14 & \text { Uberlândia }\end{array}$

2 Rio de Janeiro

Belo Horizonte

Ribeiráo Preto

8 São José do Rio Preto

1 Londrina

14 Uberlândia
29 Aracaju

30 João Pessoa

31 Fortaleza

17 Juiz de Fora

18 Governador Valadares

19 Teófilo Otoni

20 Cascavel

32 Natal

33 Crato

34 Belém

35 São Luiz

36 Imperatriz

37 Marabá

38 Campos

39 Itaperuna

40 Montes Claros

41 Muriaé

42 Manhuaçu/Manhumirim

7 Recife

28 Maceió
43 Itapemirim/Caparaó

44 Lages/Curitibanos

45 Santarém

46 Manaus

47 Purus

48 Santa Maria

49 Campanha

50 Rio Branco

51 Rondônia

52 Teresina

53 Campina Grande

54 Irecê

Fonte: LEMOS (1991). 
MAPA 18 - CARACTERIZAÇÃO DAS REGIÕES ECONÔMICAS E ÁREAS DE SUBSISTENNCIA - REGIONALIZAÇÃO 1980

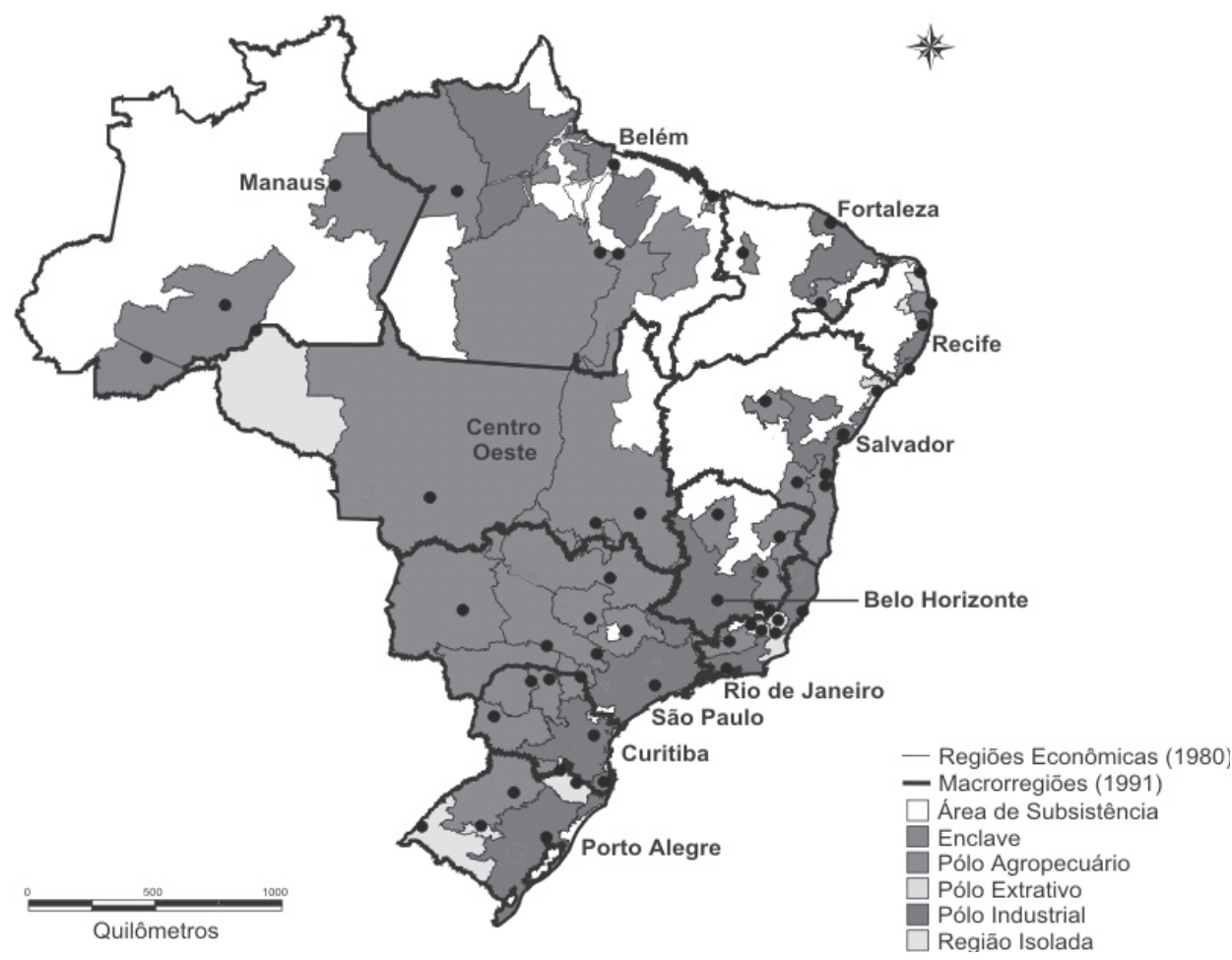

Chamamos a atenção para as principais semelhanças e diferenças entre as duas regionalizações:

1) o padrão do desenvolvimento regional brasileiro não parece ter experimentado mudança estrutural entre 1980 e 1991, uma vez que os grandes contornos geográficos da economia brasileira continuam semelhantes;

2) como a literatura tem evidenciado, as maiores mudanças estruturais do desenvolvimento regional após 1970 vão acontecer ao longo da década de 90, especialmente aquelas relacionadas ao processo de reconcentração industrial, o que torna interessante a regionalização relativa a 2000 , com os novos dados censitários; 
3) a menor incidência de pólos industriais no Norte e Nordeste e a redução de sua extensão geográfica no sul do País em 1991 deve-se, principalmente, ao critério restritivo de especialização produtiva utilizado, com QL igual ou acima do coeficiente 3;

4) o mesmo ocorre em relação à incidência dos pólos agropecuários na região Norte que, em parte, se transformam em enclaves e regiões isoladas em 1991, devido também a este critério restritivo;

5) no entanto, algumas mudanças importantes no panorama econômico regional são perceptíveis, como a emergência das regiões agrícolas de Barreiras e Petrolina-Joazeiro no Nordeste, consideradas áreas de subsistência em 1980, e da base extrativa mineral do Complexo de Carajás, que passa de "enclave agropecuário" para "enclave extrativoagropecuário", e a consolidação da fronteira agrícola de Rondônia, que se transforma em nova região agrícola;

6) a transformação do "enclave industrial" de Manaus em "região isolada industrial" não muda a natureza da caracterização da indústria local, no que toca à falta de ancoragem territorial, refletindo muito mais a maior concentração de produtos eletrônicos de consumo atraídos pela continuidade da política de incentivos fiscais. Por outro lado, a extensão geográfica das áreas de enclaves e regiões isoladas em 1980 e 1991, no Norte e Nordeste, apresenta uma distorção devido ao georreferenciamento por microrregiões, sendo que o georreferenciamento por municípios aumentaria sobremaneira as áreas de subsistência. 
QUADRO I - CARACTERIZAÇÃO DETALHADA DAS REGIÕES ECONÔMICAS E ÁREAS DE SUBSISTÊNCIA - REGIONALIZAÇA 1991

\begin{tabular}{|c|c|c|c|}
\hline \multicolumn{2}{|c|}{ Macrorregião de Belo Horizonte } & \multicolumn{2}{|c|}{ Macrorregião de Fortaleza } \\
\hline Nome do Mesopólo & Caracterização Econômica & Nome do Mesopólo & Caracterização Econômica \\
\hline Belo Horizonte & Macro Pólo Industrial & Fortaleza & Macro Pólo Turístico-Administrativo \\
\hline Divinopólis & Meso Pólo Industrial & Sobral & Enclave Agropecuário \\
\hline Ipatinga & Meso Pólo Industrial & Mossoró & Enclave Extrativo \\
\hline Governador Valadares & Meso Pólo Agropecuário & Teresina & Enclave Agropecuário \\
\hline Teófilo Otoni & Enclave Agropecuário & Cariri (Juazeiro do Norte) & Enclave Agropecuário \\
\hline Montes Claros & Enclave Agropecuário & Caxias & Enclave Agropecuário \\
\hline \multicolumn{2}{|c|}{ Macrorregião de São Paulo } & Iguatu & Enclave Agropecuário \\
\hline Nome do Mesopólo & Caracterização Econômica & \multicolumn{2}{|c|}{ Macrorregião de Recife } \\
\hline São Paulo & Macro Pólo Industrial e Financeiro & Nome do Mesopólo & Caracterização Econômica \\
\hline Campinas & Meso Pólo Industrial & Recife & Macro Pólo Industrial-Turístico \\
\hline Sorocaba & Meso Pólo Industrial & João Pessoa & Região Isolada Administrativa \\
\hline Itapetininga & Meso Pólo Industrial & Natal & Enclave Extrativo- Administrativo \\
\hline São José dos Campos & Meso Pólo Industrial & Campina Grande & Enclave Agropecuário \\
\hline Itajuba & Meso Pólo Industrial & Caruaru & Enclave Agropecuário \\
\hline Varginha & Meso Pólo Agropecuário & Macéio & Região Isolada Industrial-Administrativa \\
\hline Ribeirão Preto & Meso Pólo Industrial & Arapiraca & Enclave Agropecuário \\
\hline Uberlândia & Meso Pólo Agropecuário & \multicolumn{2}{|c|}{ Macrorregião de Belém } \\
\hline São José do Rio Preto & Meso Pólo Agropecuário & Nome do Mesopólo & Caracterização Econômica \\
\hline Bauru & Meso Pólo Industrial & Belém & Macro Pólo Industrial-Administrativo \\
\hline Marília & Meso Pólo Agropecuário & Macapá & Enclave Administrativo \\
\hline Araçatuba & Meso Pólo Industrial & Altamira & Enclave Extrativo-Agropecuário \\
\hline Presidente Prudente & Meso Pólo Agropecuário & Santarém & Enclave Extrativo-Agropecuário \\
\hline Sudoeste de Goiás & Meso Pólo Agropecuário & Marabá & Enclave Extrativo-Agropecuário \\
\hline Dourados & Meso Pólo Agropecuário & Araguína & Enclave Extrativo-Agropecuário \\
\hline Campo Grande & Meso Pólo Agropecuário & Imperatriz & Enclave Agropecuário \\
\hline \multicolumn{2}{|c|}{ Macrorregião do Rio de Janeiro } & São Luís & Enclave Extrativo-Administrativo \\
\hline Nome do Mesopólo & Caracterização Econômica & Santa Luzia & Enclave Agropecuário \\
\hline Rio de Janeiro & Macro Pólo Industrial-Turístico & \multicolumn{2}{|c|}{ Macrorregião de Porto Alegre } \\
\hline Vitória & Meso Pólo Industrial & Nome do Mesopólo & Caracterização Econômica \\
\hline Volta Redonda & Meso Pólo Industrial & Porto Alegre & Macro Pólo Industrial \\
\hline Juiz de Fora & Meso Pólo Industrial & Pelotas & Meso Pólo Agropecuário \\
\hline Campos dos Goytacazes & Meso Pólo Extrativo & Santa Maria & Meso Pólo Agropecuário \\
\hline \multicolumn{2}{|c|}{ Macrorregião do Centro Oeste } & Uruguaiana & Meso Pólo Agropecuário \\
\hline Nome do Mesopólo & Caracterização Econômica & Chapecó & Meso Pólo Agropecuário \\
\hline Brasília & Meso Pólo Administrativo & Passo Fundo & Meso Pólo Agropecuário \\
\hline Goiania & $\begin{array}{l}\text { Meso Pólo Administr.- } \\
\text { Agropecuário }\end{array}$ & Lages & Meso Pólo Industrial \\
\hline Rondonópolis & Meso Pólo Agropecuário-Extrativo & Tubarão-Criciúma & Meso Pólo Industrial \\
\hline
\end{tabular}




\begin{tabular}{|l|l|l|l|}
\hline Cuiabá & Meso Pólo Agropecuário-Extrativo & Caxias do Sul & Meso Pólo Industrial \\
\hline Ji- Paraná & Região Isolada Agropecuária & \multicolumn{2}{|c|}{ Macrorregião de Curitiba } \\
\hline Porto Velho & Região Isolada Administrativa & Nome do Mesopólo & Caracterização Econômica \\
\hline \multicolumn{2}{|c|}{ Macro Região do Salvador } & Curitiba & Macro Pólo Industrial \\
\hline Nome do Meso & Caracterização Econômica & Joinville & Meso Pólo Industrial \\
\hline Salvador & Macro Pólo Industrial-Turístico & Blumenau & Meso Pólo Industrial \\
\hline Ilhéus & Enclave Agropecuário & Florianópolis & Meso Pólo Turistico e Administrativo \\
\hline Texeira de Freitas & Enclave Agropecuário & Guarapuava & Meso Pólo Industrial \\
\hline Vitória da Conquista & Enclave Agropecuário & Toledo - Cascavel & Meso Pólo Agropecuário \\
\hline Barreiras & Região Isolada Agropecuária & Maringá & Meso Pólo Agropecuário \\
\hline Juazeiro- Petrolina & Região Isolada Agropecuária & Londrina & Meso Pólo Agropecuário \\
\hline Aracaju & Região Isolada Extrativa & & Macrorregião de Manaus \\
\hline & & Nome do Mesopólo & Caracterização Econômica \\
\hline & & Manaus & Macro Região Isolada Industrial \\
\hline & & Rio Branco & Enclave Agropecuário \\
\hline & & Boa Vista & Enclave Extrativo \\
\hline
\end{tabular}

\section{QUADRO 2 - CARACTERIZAÇÃO DETALHADA DAS REGIÕES ECO- NÔMICAS E ÁREAS DE SUBSISTÊNCIA - REGIONALIZA- ÇA 1980}

\begin{tabular}{|c|c|c|c|}
\hline \multicolumn{2}{|c|}{ Macrorregião de Belo Horizonte } & \multicolumn{2}{|c|}{ Macrorregião de Fortaleza } \\
\hline Nome do Mesopólo & Caracterização Econômica & Nome do Mesopólo & Caracterização Econômica \\
\hline Belo Horizonte & Pólo Industrial & Fortaleza & Pólo Industrial-Turístico-Administrativo \\
\hline Divinopólis & Incluído em BH & Sobral & Área de Subsistência \\
\hline Ipatinga & Incluído em BH & Mossoró & Área de Subsistência \\
\hline Governador Valadares & Pólo Agropecuário (1) & Teresina & Enclave Industrial e Administrativo \\
\hline Teófilo Otoni & Pólo Agropecuário & $\begin{array}{l}\text { Cariri (Juazeiro do } \\
\text { Norte) }\end{array}$ & Pólo Agropecuário \\
\hline Montes Claros & Enclave Agropecuário & Iguatu (Crato) & Unificado com Cariri \\
\hline \multicolumn{2}{|c|}{ Macrorregião de São Paulo } & Caxias & Área de Subsistência \\
\hline Nome do Mesopólo & Caracterização Econômica & \multicolumn{2}{|c|}{ Macrorregião de Recife } \\
\hline São Paulo & Pólo Industrial e Financeiro & Nome do Mesopólo & Caracterização Econômica \\
\hline Campinas & Incluído em SP & Recife & Pólo Industrial-Turístico-Administrativo \\
\hline Sorocaba & Incluído em SP & João Pessoa & Pólo Agropecuário-Administrativo \\
\hline Itapetininga & Incluído em SP & Natal & Pólo Extrativo-Administrativo \\
\hline São José dos Campos & Incluído em SP & Campina Grande & Região Industrial \\
\hline Itajuba & Incluído em SP & Caruaru & Área de Subsistência \\
\hline Varginha & Incluído em SP & Macéio & Pólo Agropecuário-Administrativo \\
\hline Ribeirão Preto & Pólo Agropecuário & Arapiraca & Área de Subsistência \\
\hline Uberlândia & Pólo Agropecuário & \multicolumn{2}{|c|}{ Macrorregião de Belém } \\
\hline São José do Rio Preto & Pólo Agropecuário & Nome do Mesopólo & Caracterização Econômica \\
\hline Bauru & Pólo Agropecuário & Belém & Pólo Industrial-Administrativo \\
\hline Marília & Incluído em Bauru & Altamira & Incluído em Belém \\
\hline
\end{tabular}




\begin{tabular}{|c|c|c|c|}
\hline Araçatuba & Incluído em Bauru & Macapá & Área de Subsistência \\
\hline Pres. Prudente & Pólo Agropecuário (2) & Santarém & Enclave Extrativo-Agropecuário \\
\hline Sudoeste de Goiás & Incluído em Uberlandia & Marabá & Enclave Agropecuário \\
\hline Dourados & Incluído em Campo Grande & Araguaína & Unificado com Marabá \\
\hline Campo Grande & Pólo Agropecuário-Administr. & Imperatriz & Pólo Agropecuário \\
\hline \multicolumn{2}{|c|}{ Macrorregião do Rio de Janeiro } & São Luís & Pólo Agropecuário-Administrativo \\
\hline Nome do Mesopólo & Caracterização Econômica & Santa Luzia & Incluído em São Luis \\
\hline Rio de Janeiro & Pólo Industrial-Turístico-Administr. & \multicolumn{2}{|c|}{ Macrorregião de Porto Alegre } \\
\hline Vitória & Pólo Industrial e Administrativo (3) & Nome do Mesopólo & Caracterização Econômica \\
\hline Volta Redonda & Incluído no RJ & Porto Alegre & Pólo Industrial \\
\hline Juiz de Fora & Pólo Agropecuário (4) & Pelotas & Incluído em Porto Alegre \\
\hline Campos dos Goytacazes & Região Agropecuário (5) & Santa Maria & Região Isolada Agropecuária \\
\hline \multicolumn{2}{|c|}{ Macrorregião do Centro Oeste } & Uruguaiana & Regiáo Isolada Agropecuária \\
\hline Nome do Mesopólo & Caracterização Econômica & Chapecó & Unificado com Passo Fundo \\
\hline Brasília & Pólo Administrativo-Agropecuário & Passo Fundo & Pólo Agropecuário \\
\hline Goiania & Unificado com Brasília & Lages & Região Isolada Agropecuária \\
\hline Rondonópolis & Incluído em Cuiabá & Tubarão-Criciúma & Incluído em Florianópolis \\
\hline Cuiabá & Pólo Agropecuário-Administr. & Caxias do Sul & Incluído em Porto Alegre \\
\hline Ji-Paraná & Região Isolada de Fronteira Rondônia & \multicolumn{2}{|c|}{ Macrorregião de Curitiba } \\
\hline Porto Velho & Unificado com Ji-Paraná & Nome do Mesopólo & Caracterização Econômica \\
\hline \multicolumn{2}{|c|}{ Macrorregião do Salvador } & Curitiba & Pólo Industrial \\
\hline Nome do Mesopólo & Caracterização Econômica & Joinville & Incluído em Curitiba \\
\hline Salvador & Pólo Industrial-Turístico-Administr.(6) & Blumenau & Incluído em Curitiba \\
\hline llhéus & Pólo Agropecuário & Florianópolis & Pólo Industrial-Turístico-Administrativo \\
\hline Texeira de Freitas & Unificado com llhéus & Guarapuava & Incluído em Curitiba \\
\hline Vitória da Conquista & Pólo Agropecuário & Toledo - Cascavel & Pólo Agropecuário \\
\hline Barreiras & Área de Subsistência & Maringá & Pólo Agropecuário \\
\hline Juazeiro- Petrolina & Área de Subsistência & Londrina & Pólo Agropecuário \\
\hline Aracaju & Pólo Extrativo-Administr. & \multicolumn{2}{|c|}{ Macrorregião de Manaus } \\
\hline & & Nome do Mesopólo & Caracterização Econômica \\
\hline & & Manaus & Enclave Industrial (7) \\
\hline & & Rio Branco & Enclave Agropecuário \\
\hline & & Boa Vista & Enclave Extrativo \\
\hline
\end{tabular}

Desmembramentos Regionalização 1980: (1) Região Isolada Agropecuário de Manhuaçu/ Manhumirim; (2) Pólo Agropecuário de Ourinhos; (3) Região Isolada Agropecuária de Itapemirim/Caparaó; (4) Região Agropecuária de Muriaé; (5) Região Isolada Agropecuária de Itaperuna; (6) Enclave Agropecuário de Irecê; (7) Enclave Agropecuário de Purus. 


\section{COMENTÁRIOS FINAIS}

O presente trabalho procurou explorar os aspectos centrais do esforço metodológico e empírico de uma nova proposta de regionalização econômica do Brasil, consubstanciada no projeto de pesquisa desenvolvido pelos autores. (LEMOS et. al., 2000). Mesmo que constituindo uma configuração geográfica datada, os resultados comparativos com 1980 evidenciaram os aspectos econômicos estruturais imersos no território nacional.

Do ponto de vista metodológico, utilizamos uma versão de modelo gravitacional adaptado à disponibilidade dos dados, cuja principal base de informações foram os microdados do Censo Demográfico de 1991 e a base cartográfica digital da Malha Municipal Digital do Brasil, convertida para o Mapinfo. A aplicação desta metodologia se deu via utilização do Sistema de Informações Geográficas - SIG. Este procedimento possibilita a identificação georrefenciada das regiões pólo e suas áreas de influência, com base no potencial de interação econômica entre as unidades espaciais e a correspondente hierarquia de poder de atração econômica no espaço.

Os resultados empíricos, obtidos pelo estudo, configuram as regiões que compõem o que se poderia denominar de um olhar sobre a geografia econômica do Brasil contemporâneo. Isto porque os critérios escolhidos definem os resultados da regionalização. Esta, por sua vez, é por natureza datada temporalmente, constituindo apenas um retrato do campo de forças - centrípetas e centrífugas - no espaço em momento específico. Como essas forças estão em constante movimento, é possível que os resultados de uma nova regionalização para 2000, com os dados do novo censo demográfico, sejam diferentes dos obtidos neste estudo, mesmo replicando os mesmos critérios metodológicos. O que não torna inócuo o esforço realizado é o fato do sistema regional conter forte componente estrutural, em razão da relativa estabilidade da rede urbana e das trocas inter-regionais, cuja dinâmica resulta de processos históricos que conformam configurações espaciais específicas no contexto de polarização nacional. No caso do desenvolvimento regional brasileiro recente, essa configuração do espaço econômico regional ocorre em virtude de vantagens ou desvantagens de localização em relação à proximidade ou distância do pólo nacional de São Paulo e, secundariamente, do Rio de Janeiro. Graças aos efeitos de transbordamento e acessibilidade, as 
áreas próximas de influência direta do pólo de São Paulo possuem vantagens de forte integração industrial intra-regional. Tais vantagens são decorrentes da integração geográfica intersetorial e da escala urbana, capazes de ofertar um amplo espectro de serviços superiores ligados à produção industrial, como infra-estrutura de conhecimento, havendo, neste caso, uma efetiva rede de cidades economicamente integradas.

No caso do Rio de Janeiro, essas vantagens reveladas de integração produtiva do todo regional são fortemente restringidas, já que as áreas de influência possuem especializações fragmentadas que não surgem, historicamente, de um transbordamento do lugar central original, o que traz uma grande heterogeneidade intra-regional. Os macropólos regionais com influência direta de São Paulo, nos casos de Curitiba e Belo Horizonte, comportam vantagens potenciais a serem exploradas, dada a possibilidade de uma integração produtiva inter-regional com a indústria paulista, capaz de gerar economias de especialização, as quais, no entanto, podem ser prejudicadas por um insuficiente nível de desenvolvimento urbano.

No caso de macropólos regionais mais distantes do pólo primaz paulista, suas posições relativas dependem de como estejam inseridos nacionalmente. Os macropólos de Porto Alegre e o multipólo do Centro-Oeste certamente possuem nível elevado de integração produtiva com São Paulo, participando, com suas especializações, da divisão inter-regional do trabalho. No entanto, Porto Alegre está perdendo posição relativa ante ao macropólo de Curitiba, que já influencia diretamente a parte mais dinâmica do Estado de Santa Catarina. O espaço multipolarizado do Centro-Oeste, por sua vez, parece estar no início de uma configuração mais definitiva de suas forças de polarização, à medida que consolida sua rede urbana, a partir da exploração de suas vantagens baseadas em recursos naturais e amplia sua integração produtiva e comercial ao macropólo paulista.

No caso do Nordeste, com macropólos constituídos por entornos de subsistência, a questão do desenvolvimento regional e local é mais complexa e demanda um esforço de criação de fatores locacionais de caráter regionalmente competitivo, bem como de geração de novas combinações da produção que estabeleçam uma ancoragem ou lock in locacional, com 
ampliação da densidade urbana da rede regional de cidades. Por sua vez, os vazios econômicos dos macropólos do Norte não configuram a ausência de áreas econômicas bem delimitadas, as quais refletem principalmente o desenvolvimento de Belém e seu entorno macrorregional, cuja base mineral extensa parece experimentar um processo de adensamento de seus elos produtivos.

\section{REFERÊNCIAS BIBLIOGRÁFICAS}

ANDRADE, T.; SERRA, R. Estimativas para o Produto Interno Bruto dos municípios brasileiros: 1975, 1980, 1985 e 1996. Rio de Janeiro: IPEA, 1996, Mimeografado.

CHRISTALLER, W. The central places in southern Germany. Englewood Cliffs, NJ: Prentice- Hall, 1966.

DINIZ, C. C. Desenvolvimento poligonal no Brasil: nem desconcentração nem contínua polarização. Revista Nova Economia, Belo Horizonte,v. 3, n. 1, 1993.

FERREIRA, C. M. de C. Um estudo de regionalização do Estado de Minas Gerais por meio de um modelo potencial. Belo Horizonte: CEDEPLAR, 1971.

FUJITA, M.; KRUGMAN, P.; VENABLES, A. J. The spatial economy: cities, regions and international trade. Cambridge: MIT Press, 1999.

IBGE. Censo demográfico: Brasil. Rio de Janeiro: IBGE, 1980, 1991.

ISARD, W.; BRAMAHALL, D. F. Methods of regional analysis: an introduction to regional science. New York: Wiley, 1960.

IPEA/IBGE/NESUR (IE-UNICAMP). Caracterização e tendências da rede urbana do Brasil. Volumes 1 e 2. Campinas: UNICAMP, 1999.

LEMOS, Maurício B. Duas técnicas de análise regional elaboradas a partir de categorias espaciais: a regionalização e o método estrutural- diferencial. 1991. Tese de Professor Titular, Departamento de Ciências Econômicas, UFMG, Belo Horizonte.

LEMOS, Mauro B.; DINIZ, C. C.; GUERRA, L. P., MORO, S. A nova geografia econômica do Brasil: uma proposta de regionalização com base nos pólos econômicos e suas áreas de influência. Anais do IX Seminário sobre a Economia Mineira (mesa especial), Diamantina, 2000.

LOSCH, A. The economics of location. New Haven: Yale University Press, 1954. 
NORTH, D. C. Teoria da localização e crescimento econômico regional. In: SCHWARTZMAN, J. (org.), Economia regional: textos escolhidos. Belo Horizonte: CEDEPLAR/CETREDE - MINTER, 1977.

PERROUX, F. L'économie du XXème siècle. Paris: PUF, 1961.

RICHARDSON, H. W. Elementos de economia regional. Rio de Janeiro: Zahar, 1973.

Este trabalho é parte da pesquisa Dinâmica Demográfica, Desenvolvimento Regional e Políticas Públicas, financiada pelo PRONEX, Programa de Apoio a Núcleos de Excelência, consórcio CNPq/ Capes/Finep. Nossos agradecimentos ao parecerista anônimo da Estudos Econômicos. Suas sugestões foram decisivas para o aprimoramento deste artigo.

Agradecemos aos assistentes de Pesquisa da Equipe Economia Regional/CEDEPLAR: Bernardo Palhares Campolina Diniz e Rodrigo Fortini Boschi (1999-2001); Rangel Galinari (2002-2003). Endereço: CEDEPLAR/UFMG, Rua Curitiba 832 - CEP 30170-120, Belo Horizonte - MG, Tel.: (031) 279-90 83 e Fax :(031) 201-3657, e-mail: mbl@,cedeplar.ufmg.br (Recebido em outubro de 2002. Aceito para publicação em julho de 2003). 